\title{
ANÁLISE DA EFICIÊNCIA DOS DEPARTAMENTOS DE ECONOMIA DE INSTITUIÇÕES DE ENSINO SUPERIOR DO BRASIL
}

\author{
Aléssio Tony Cavalcanti de Almeida* \\ Hilton Martins de Brito Ramalho ${ }^{\dagger}$ \\ EryKa Fernanda Miranda Sobral ${ }^{\ddagger}$ \\ Andrea Ferreira da Silva ${ }^{\S}$
}

\begin{abstract}
Resumo
Este artigo examina a eficiência dos departamentos de economia no Brasil, considerando os resultados de ensino e pesquisa. O método de Análise Envoltória de Dados com fronteira sequencial e replicações bootstrap foi usado para estimar os escores de eficiência no período de 2009 e 2012. Tais estimativas foram condicionadas, em uma análise de regressão, à indicadores socioeconômicos dos alunos e das instituições em um modelo com efeitos fixos. Os resultados mostram que o nível de eficiência técnica dos departamentos, em média, reduziu de $80 \%$ para $64 \%$ no período, ao passo que a eficiência de escala foi sempre superior a $93 \%$. Ademais, os departamentos compostos por alunos com melhores condições socioeconômicas tendem a apresentar um maior nível de eficiência técnica.
\end{abstract}

Palavras-chave: Economia; Educação Superior; Eficiência; DEA; Regressão.

\begin{abstract}
This article investigates the efficiency of economics departments in Brazil, considering the results of teaching and research. We use Data Envelopment Analysis with sequential frontier and bootstrap replications to estimate the efficiency scores between 2009 and 2012. Theses estimates were conditioned to socioeconomic indicators of students and higher education institutions in a fixed effects model. The results show that the technical efficiency level of the departments, on average, decreased from $80 \%$ to $64 \%$ in the period, while the scale efficiency was always higher than $93 \%$. In addition, departments composed of students with better socioeconomic backgrounds tend to have a higher level of technical efficiency.
\end{abstract}

Keywords: Economics; Higher Education; Efficiency; DEA: Regression. JEL classification: I21, I23, C14

DOI: http://dx.doi .org/10.11606/1980-5330/ea122240

\footnotetext{
* Programa de Pós-Graduação em Economia, Universidade Federal da Paraíba - PPGE/UFPB. Email: alessio@ccsa.ufpb.br

† PPGE/UFPB. E-mail: hilton@ccsa.ufpb.br.

‡ PPGE/UFPB. E-mail: fmsobral@hotmail.com.

$\S$ PPGE/UFPB. E-mail: andrea.economia@yahoo.com.br.
} 


\section{Introdução}

O ensino de Ciências Econômicas tem longa tradição no Brasil. Conforme relata de Castro (2001), seu início esteve atrelado aos cursos de Técnicas Comerciais, Direito e Engenharia desde o período colonial. Todavia, apenas em 1946 foi criado o primeiro curso oficial de economia integrado à Universidade do Brasil, através da Faculdade Nacional de Ciências Econômicas. A partir dos anos de 1950, vários cursos de economia surgiram em todo país. Em 2012, dados do Censo da Educação Superior apontavam que o Brasil contava com 250 cursos de graduação em economia em 196 instituições de ensino superior. Ademais, conforme o relatório de avaliação trienal dos programas de pós-graduação em economia 2010-2012, existiam 55 cursos de Mestrado e 26 de Doutorado.

Ao se comparar as estruturas curriculares de vários cursos das áreas sociais (Administração, Contabilidade e Direito), é possível perceber que o ensino de economia vem requerendo cada vez mais uma maior base de conhecimento em Matemática e em Estatística, dado o crescente emprego de modelos teóricos formalizados, replicáveis e com predições passíveis de testes empíricos. Por outro lado, é bastante conhecida a dificuldade dos estudantes brasileiros com Matemática, como pode ser constatado nos resultados da Prova Brasil, do Exame Nacional do Ensino Médio (ENEM) e na posição do país no ranking do Programa Internacional de Avaliação de Estudantes ${ }^{1}$ (PISA). Tais características, conjugadas à imprecisão das atribuições da profissão de economista no mercado de trabalho, parecem respaldar os altos índices de retenção e evasão escolar observados nos cursos de Ciências Econômicas.

Conforme dados do Exame Nacional de Desempenho dos Estudantes (ENADE) para o ano de 2012, o tempo médio de conclusão de um estudante do Curso de Economia é o maior dentre alguns cursos da área de Ciências Sociais (Administração, Contabilidade e Direito). Em média, um estudante de economia leva 5,2 anos para se graduar, independentemente do turno e da rede administrativa da Instituição de Ensino Superior (IES). Esse tempo passa para 6,5 anos, quando se consideram alunos de IES públicas matriculados no período da noite ${ }^{2}$. Além desse fator, os cursos de graduação em economia no país têm uma alta taxa de evasão $(60 \%)$, conforme estimativas a partir do Censo Superior de 2012. No período de 2009 e 2012, observam-se também mudanças significativas nas condições de oferta dos cursos de economia no país. Conforme dados do Censo Superior, houve um crescimento de $65 \%$ no número de departamentos nas IES públicas, muito embora tenha ocorrido uma redução no total de departamentos em 3\%, em decorrência do fechamento de cursos ofertados por IES privadas.

Diante desse quadro, torna-se relevante investigar como as práticas de ensino e de alocação de recursos dos departamentos de economia no Brasil vêm repercutindo na formação de estudantes e na produção acadêmica na área. Enquanto unidades tomadoras de decisão, alguns departamentos podem combinar insumos disponíveis (corpo docente, corpo discente, corpo técnico e infra-

\footnotetext{
${ }^{1}$ Por exemplo, no PISA de 2012, o Brasil ficou na posição $58^{\circ}$ dentre 65 países na média do exame de Matemática (Organization for Economic Co-operation and Development 2014).

${ }^{2}$ Vale ressaltar que a maioria dos estudantes de economia estão matriculados em horário noturno. Ademais, quando se compara o indicador de tempo de conclusão para o curso de economia entre IES públicas e privadas no turno da manhã, essa diferença é de 1 ano, enquanto que no período noturno, passa para 1,7 anos, conforme microdados do ENADE de 2012.
} 
estrutura) de modo a produzir resultados eficientes nas dimensões de ensino e pesquisa. Tais práticas de excelência podem servir de referência para outras unidades se ajustarem na busca de melhores resultados e orientar políticas governamentais na área de educação superior.

Ao contrário de estudos realizados para outros países (Maddena et al. 1997, Johnes 2006a, Kao \& Hung 2008, Halkos et al. 2012, Aziz et al. 2013), no Brasil pouco se conhece a respeito do desempenho dos departamentos de cursos de ensino superior na oferta de serviços educacionais e produção científica, em especial na área de economia. A maioria dos estudos realizados nesse campo de análise se limitam a comparações agregadas por IES (Belloni 2000, Façanha \& Marinho 2001, Costa et al. 2012, 2015), não considerando possíveis efeitos específicos a cada gestão departamental e área do conhecimento científico. Por outro lado, apesar de alguns desses estudos apontarem para a importância de diferenças regionais na discriminação de práticas eficientes, não há ponderações para aspectos associados ao lado da demanda por cursos superiores, especialmente em termos de condições contextuais dos alunos. Neste caso, cursos que atraem discentes com melhor background poderiam produzir rendimento acadêmico superior vis-à-vis a cursos com discentes de condições diferentes, o que afetaria a comparabilidade da produtividade entre os departamentos (Joumady \& Ris 2005, Johnes 2006b).

Esse estudo, portanto, procura contribuir para a discussão em destaque ao comparar os departamentos de economia no Brasil em termos de práticas eficientes na oferta de formação superior e produção acadêmica. Para tanto, emprega-se, inicialmente, a abordagem de Análise Envoltória de Dados com Fronteira Sequencial (DEA-S) e bootstrap, levando em consideração insumos dos departamentos e variáveis de resultado referentes ao ensino e à pesquisa. Em seguida, os escores de eficiência são condicionados à indicadores socioeconômicos dos alunos, para verificar o quanto da eficiência técnica dos departamentos podem ser atribuíveis a qualidade do corpo discente.

Afora essa introdução, esse artigo está organizado da seguinte forma: a Seção 2 apresenta uma revisão da literatura especializada; a Seção 3 aborda os métodos adotados; na Seção 4 são discutidos os procedimentos de tratamento e uso de dados; na Seção 5 é feita uma discussão dos resultados e, por fim, a Seção 6 é reservada às considerações finais.

\section{Revisão da Literatura}

Alguns estudos documentados na literatura especializada se preocuparam em mensurar a eficiência de IES em diversos países. De forma geral, é possível encontrar trabalhos científicos com comparações entre diferentes instituições e entre diferentes departamentos dentro de uma mesma instituição, ou de modo mais restrito, pesquisas direcionadas a um determinado curso dentre diferentes instituições. Em sua maioria, esses estudos utilizam a metodologia DEA, haja vista a possibilidade de construção flexível de fronteiras de produção do setor educacional mediante o uso de múltiplos insumos e múltiplos produtos (Casado \& Souza 2007, Costa et al. 2012). A Tabela 1, a seguir, sumariza os principais inputs e outputs utilizados pela literatura.

Um exemplo desse tipo de avaliação é o estudo de Maddena et al. (1997), em que foi analisada a eficiência dos departamentos de economia das universidades australianas, comparando entidades que receberam financiamento do 
Governo para pesquisa e ensino com aqueles que não foram contemplados. Com o intuito de fornecer uma avaliação quanto ao sucesso de tal investimento em reduzir o hiato de eficiência entre os departamentos de economia, o estudo fez uma avaliação da eficácia dos programas do governo australiano em 24 universidades entre os anos de 1987 e 1991. Assim, por meio da aplicação DEA, foram utilizados os seguintes insumos (inputs): publicações oriundas das pesquisas, número de funcionários por departamento (administrativos e docentes), qualificações dos profissionais e o número de estudantes de graduação; e como produtos (outputs): o número de estudantes concluintes da graduação e o número de concluintes do curso de pós-graduação. Por fim, concluíram que, todos os departamentos de economia alcançaram ganhos de eficiência, enquanto que a diferença entre o desempenho das universidades contempladas com o programa de incentivo a pesquisa e as que não receberam tal política reduziu-se ao longo do tempo.

Joumady \& Ris (2005) investigaram o efeito das instituições de ensino superior na vida profissional dos alunos recém formados na graduação. Para uma amostra de estudantes provenientes de 210 instituições de um grupo de oito países europeus (Itália, Espanha, França, Áustria, Finlândia, Grã-Bretanha, Alemanha e Holanda), foram aplicados questionários após três anos de formados. Usando o método DEA, os referidos autores analisaram três modelos de eficiência: i) o primeiro (modelo de competências), referindo-se ao que a universidade acrescentou em termos de formação utilizou por inputs: notas de entrada na universidade, qualidade dos professores e qualidade de materiais didáticos utilizados na formação do aluno e, por outputs: nível de competência vocacional adquirida (conhecimento teórico e de métodos) e de competência genérica adquirida (solucionar problemas, competência analítica, habilidade para aprender); ii) o segundo (modelo de ajustamento), sob o pressuposto de que a universidade deve gerar competências que correspondam às necessidades no mercado de trabalho, estimou a eficiência da aprendizagem após a conclusão do curso no emprego do aluno utilizando como inputs: o número de tentativas que o aluno na procura por emprego, duração do trabalho e importância do conhecimento adquirido na universidade para o trabalho (background do estudo) e, como outputs: a diferença entre o nível de competência vocacional adquirida e necessária, a diferença de competência genérica adquirida e necessária e a distância entre o que se aprendeu e o que se necessita no trabalho atual; iii) por fim, no terceiro modelo, realizou uma análise global (junção do primeiro e segundo modelo).

Os resultados do trabalho de Joumady \& Ris (2005) sugerem que as universidades britânicas, holandesas e austríacas são as mais eficientes; as espanholas, finlandesas e italianas são consideradas menos eficientes; e poucas foram as instituições eficientes para os três modelos, demonstrando a necessidade de uma maior transferência de conhecimento em conformidade com as competências requeridas no mercado de trabalho de cada país.

Já Johnes (2006a) concentrou-se em examinar a eficiência no contexto do ensino superior para um conjunto de mais de 100 instituições da Inglaterra nos anos de 2000 e 2001. Esse estudo utilizou quatro inputs: quantidade e qualidade dos alunos de graduação e pós-graduação, despesas de administração, número de docentes em tempo integral e valor dos pagamentos de juros e amortização. Também foram empregados os seguintes outputs: o conceito do curso de pós-graduação, total de graduados saindo dos cursos e pesquisas. Seus resultados sugeriram que enquanto os níveis de inputs e outputs diferem 
Tabela 1: Sumarização da literatura sobre a eficiência de cursos, departamentos e universidades

\begin{tabular}{|c|c|c|c|}
\hline Estudo & Objeto de estudo & Inputs & Outputs \\
\hline $\begin{array}{l}\text { Maddena et al. } \\
(1997)\end{array}$ & $\begin{array}{l}24 \text { departamentos de econo- } \\
\text { mia de universidades austra- } \\
\text { lianas em } 1987 \text { e } 1991\end{array}$ & Docentes e pesquisadores & $\begin{array}{l}\text { Concluintes da graduação e da pós-graduação; publica- } \\
\text { ção de artigos }\end{array}$ \\
\hline Belloni (2000) & $\begin{array}{l}33 \text { universidades federais } \\
\text { brasileiras }\end{array}$ & Docentes & $\begin{array}{l}\text { Concluintes da graduação e da pós-graduação, artigos } \\
\text { publicados e indicador de qualidade da pós-graduação }\end{array}$ \\
\hline $\begin{array}{l}\text { Façanha \& Marinho } \\
\text { (2001) }\end{array}$ & $\begin{array}{l}\text { Instituições de ensino supe- } \\
\text { rior brasileiras de } 1995 \text { a } \\
1998\end{array}$ & $\begin{array}{l}\text { Docentes (total, tempo integral e parcial); técni- } \\
\text { cos administrativos }\end{array}$ & $\begin{array}{l}\text { Total de ingressantes por meio do vestibular, docentes } \\
\text { com doutorado; total de cursos, total de matrículas por } \\
\text { grandes áreas }\end{array}$ \\
\hline $\begin{array}{l}\text { Joumady \& Ris } \\
\text { (2005) }\end{array}$ & $\begin{array}{l}210 \text { instituições de um } \\
\text { grupo de oito países euro- } \\
\text { peus }\end{array}$ & $\begin{array}{l}\text { Notas de entrada na universidade, qualidade dos } \\
\text { professores e qualidade de materiais didáticos e } \\
\text { demais utilizados na formação do aluno; número } \\
\text { de tentativas que o aluno buscou emprego, dura- } \\
\text { ção do trabalho e importância do conhecimento } \\
\text { adquirido na universidade para o trabalho (back- } \\
\text { ground do estudo) }\end{array}$ & $\begin{array}{l}\text { Conhecimento teórico; habilidade para aprender e solu- } \\
\text { cionar problemas; a diferença entre o nível de competên- } \\
\text { cia vocacional adquirida e necessária e a diferença sobre } \\
\text { o que se aprendeu e o que se necessita para trabalhar }\end{array}$ \\
\hline Johnes $(2006 a)$ & $\begin{array}{l}100 \text { instituições inglesas no } \\
\text { ano acadêmico } 2000 / 2001\end{array}$ & $\begin{array}{l}\text { Docentes; índice de quantidade e qualidade dos } \\
\text { ingressos da graduação; recursos financeiros (de- } \\
\text { preciação, juros e gastos com biblioteca e admi- } \\
\text { nistração central), excluindo os custos de pessoal } \\
\text { docente }\end{array}$ & $\begin{array}{l}\text { Índice de quantidade e qualidade da graduação; con- } \\
\text { cluintes da pós-graduação; financiamento de pesquisas }\end{array}$ \\
\hline Johnes $(2006 b)$ & $\begin{array}{l}2.547 \text { alunos de graduação } \\
\text { em economia de universida- } \\
\text { des do Reino Unido em } 1993\end{array}$ & $\begin{array}{l}\text { Notas de entrada, gênero e estudou em escola de } \\
\text { ensino médio independente }\end{array}$ & Medidas de habilidades acadêmicas \\
\hline $\begin{array}{l}\text { Casado \& Souza } \\
(2007)\end{array}$ & $\begin{array}{l}\text { Cursos de graduação presen- } \\
\text { ciais da área de Engenharia } \\
\text { de Produção de instituições } \\
\text { de ensino superior brasilei- } \\
\text { ras }\end{array}$ & $\begin{array}{l}\text { Nota da infraestrutura, nota de organização } \\
\text { didática pedagógica, proporção de professores } \\
\text { mestres, proporção de professores doutores, pro- } \\
\text { porção de professores com regime integral ou } \\
\text { parcial e número de vagas no ano do ENADE }\end{array}$ & $\begin{array}{l}\text { Nota do ENADE e número de concluintes no ano de apli- } \\
\text { cação do ENADE }\end{array}$ \\
\hline Kao \& Hung (2008) & $\begin{array}{l}41 \text { departamentos da Uni- } \\
\text { versidade Nacional de } \\
\text { Cheng Kung em Taiwan }\end{array}$ & $\begin{array}{l}\text { Número de funcionários; despesas operacionais } \\
\text { e espaço usado por cada departamento na insti- } \\
\text { tuição }\end{array}$ & $\begin{array}{l}\text { Total de crédito de horas por docente; publicações; finan- } \\
\text { ciamento externo }\end{array}$ \\
\hline $\begin{array}{l}\text { Worthington \& Lee } \\
\text { (2008) }\end{array}$ & $\begin{array}{l}35 \text { universidades australia- } \\
\text { nas entre } 1998 \text { e } 2003\end{array}$ & $\begin{array}{l}\text { Docentes e técnicos administrativos; despesas } \\
\text { não laborais e de investigação; carga-horária da } \\
\text { graduação e pós-graduação }\end{array}$ & $\begin{array}{l}\text { Concluintes da graduação e pós-graduação; bolsas de pu- } \\
\text { blicações oficiais e dos setores nacionais }\end{array}$ \\
\hline Aziz et al. (2013) & $\begin{array}{l}22 \text { departamentos acadêmi- } \\
\text { cos de uma universidade da } \\
\text { Malásia }\end{array}$ & $\begin{array}{l}\text { Número de docentes e técnicos administrativos; } \\
\text { despesas operacionais anuais }\end{array}$ & Concluintes; financiamento de pesquisas; publicações \\
\hline $\begin{array}{l}\text { Costa et al. (2012) e } \\
\text { Costa et al. (2015) }\end{array}$ & $\begin{array}{l}49 \text { Institutos federais de en- } \\
\text { sino superior do Brasil no } \\
\text { período de } 2004 \text { a } 2008\end{array}$ & $\begin{array}{l}\text { Custo corrente por aluno, número de alunos em } \\
\text { tempo integral por docentes, número de alunos } \\
\text { em tempo integral por funcionários e índice de } \\
\text { qualificação do corpo docente }\end{array}$ & $\begin{array}{l}\text { Alunos formados por alunos matriculados e conceito da } \\
\text { Coordenação de Aperfeiçoamento de Pessoal de Nível Su- } \\
\text { perior (CAPES) para a pós-graduação }\end{array}$ \\
\hline
\end{tabular}


entre as instituições inglesas, os índices de eficiência obtidos entre elas não são significativamente diferentes. Dessa forma, o autor em destaque mostrou que há eficiência geral em todas as IES da Inglaterra e que o alto nível de eficiência merece uma discussão mais aprofundada.

Em uma investigação mais restrita, Johnes (2006b) aplicou a DEA a fim de avaliar a eficiência de ensino para o curso de graduação em economia de 2.547 universidades do Reino Unido em 1993, comparando os resultados de nível agregado e individual das DEAs. Nesse trabalho, o referido autor seguiu uma metodologia desenvolvida pela economia da educação, em que a eficiência individual é decomposta em dois elementos: um atribuível à instituição em que o aluno estudou, e o outro atribuível ao próprio estudante. Utilizando como input a nota de entrada do aluno na universidade, o gênero e se frequentou escolas privadas, para dados individuais; e, a média da universidade em relação as demais e o percentual de graduados do gênero feminino e que frequentaram escolas privadas, para dados do departamento. Por sua vez, como output utilizou, o aproveitamento acadêmico. Seus resultados mostraram que utilizar DEA para um nível agregado, que inclui tanto o componente institucional dos departamentos como o individual dos alunos, produz resultados enganosos, pois não se sabe se os esforços para aumentar a eficiência foram provenientes dos alunos ou das próprias instituições. Ademais, a análise em nível individual permite identificar para cada instituição se é o esforço que seus alunos colocam no estudo ou se é seu desempenho em relação as demais instituições que limita o aumento de eficiência. Isso tem implicação na escolha da estratégia para aperfeiçoar seu desempenho.

Kao \& Hung (2008) avaliaram a eficiência de 41 departamentos acadêmicos da Universidade Nacional de Cheng Kung, em Taiwan, por meio da DEA. Para essa, utilizaram como inputs: a quantidade de pessoas trabalhando nos departamentos, despesas operacionais e espaço; e como os outputs: as cargas horárias, publicações e doações externas. Os escores de eficiência indicaram que os departamentos devem utilizar os recursos recebidos do governo de forma mais eficiente, tendo em vista, a redução que os subsídios governamentais por estudantes às universidades sofreram nos últimos anos. Ademais, essa eficiência pode ser alcançada não apenas investigando os resultados educacionais produzidos pelo departamento, mas também investigando a utilização dos recursos na produção desses resultados.

Por sua vez, Worthington \& Lee (2008) utilizando a metodologia DEA, por meio do método não paramétrico do índice Malmquist, conseguiram decompor o crescimento da produtividade de 35 universidades australianas em dois elementos: mudança na eficiência técnica ao longo do tempo (catch-up) e mudanças na tecnologia (frontier-shift effect) ao longo do tempo. Assim, foram empregados os seguintes inputs: o pessoal docente e não docente, as despesas não laborais e de investigação, bibliotecas, serviços públicos, carga horária de graduação, carga horária de estudantes de pós-graduação, e como outputs: o número de concluintes de graduação, mestrado e doutorado, bolsas e publicações. Eles concluíram que o crescimento anual de produtividade média de 3,3 pontos percentuais, para todas as universidades, foi em grande parte atribuível ao progresso tecnológico (deslocamento para cima da fronteira), a partir de ganhos feitos pelas universidades na oferta de serviços de biblioteca eletrônica, gerenciamento de estudantes online e, intercâmbio de estudantes.

Aziz et al. (2013) também investigaram a eficiência para departamentos acadêmicos, porém, na Malásia. A partir do método DEA, considerando como 
inputs: o número de docentes, o número de técnicos e as despesas operacionais anuais, e como outputs: o número de graduados por ano, número de concessão de pesquisas por órgãos financiadores e o número de publicações acadêmicas por membros do corpo docente, identificaram que quase todos os departamentos utilizam eficientemente os seus recursos para produzirem capital humano (estudantes formados) para o mercado de trabalho.

Em relação aos trabalhos documentados na literatura nacional, destaca-se o estudo de Belloni (2000), que construiu indicadores de eficiência produtiva e por meio da metodologia DEA realizou uma avaliação de eficiência para 33 universidades federais brasileiras. Este autor empregou três modelos, em que o input era sempre o mesmo, isto é, o número de professores. No primeiro modelo o número total de formandos foi usado como output, para o segundo o número total de formandos e o número de artigos publicados, e para o terceiro o número total de formandos, o número de artigos publicados e um indicador da qualidade da pós-graduação, a partir dos quais foi verificada que a propriedade de retornos constantes à escala não se aplica ao caso das universidades públicas federais. Assim, a partir dessa evidência, seus resultados foram produzidos de acordo com o modelo DEA-BCC, com retornos variáveis à escala, que o levou a concluir que apenas seis das 33 universidades federais avaliadas foram consideradas tecnicamente eficientes e que as maiores possibilidades de crescimento da produtividade concentram-se em alterações nos projetos acadêmicos da maioria das universidades, na direção de uma ênfase maior nas atividades de pesquisa.

Façanha \& Marinho (2001), também por meio da DEA, desenvolveram um estudo sobre as informações divulgadas pelos Censos de Ensino Superior dos anos de 1995, 1996, 1997 e 1998, relativos às atividades das IES e referentes a programas de pós-graduações brasileiros. Eles compararam o desempenho das grandes regiões brasileiras, entre as diferentes naturezas administrativas das IES e entre as grandes áreas do conhecimento. Para a referida análise, foram empregadas como variáveis inputs: o total de docentes (em tempo integral e parcial), o total de docentes com doutorado e o total de servidores. Já os outputs foram: o total de ingressantes por meio do vestibular, o total de cursos, o total de concluintes, o total de matrículas realizadas em diversas áreas e inscrições em primeira opção. Seus achados indicam que heterogeneidades regionais são importantes na discriminação dos indicadores de eficiência. Apesar do aumento expressivo da eficiência relativa das IES, os autores em foco sugerem a necessidade de ajustes, apontando para a possibilidade de expansão do sistema educacional.

Na mesma linha, Casado \& Siluk (2012) analisaram a eficiência dos cursos de graduação presenciais da área de Engenharia de Produção nas IES brasileiras, levando em consideração aspectos de desempenho organizacional e de qualidade, a partir da DEA e da análise de fronteira invertida para certificar o resultado. Para a referida análise, utilizaram a base de dados do ENADE tratando como inputs: a nota da infraestrutura, a nota de organização didática pedagógica, a proporção de professores mestres, a proporção de professores doutores, a proporção de professores com regime integral ou parcial e o número de vagas no ano do ENADE, e como outputs: a nota do ENADE e o número de concluintes no ano de aplicação do ENADE. Dentre suas principais conclusões pode-se destacar que as instituições devem adequar sua cesta de insumos, para atingir um nível de eficiência ótimo, como por exemplo, buscar elevar sua nota no ENADE e utilizar-se de estratégias educacionais para 
aumentar o número de concluintes.

O estudo de Costa et al. (2012) é outro trabalho de destaque para o Brasil. Estes autores estimaram a fronteira de produção educacional para institutos federais (IFS) brasileiros no período de 2004 a 2008. Por meio do método DEA-SBM (Slacks Based Measure), no formato de folgas, consideraram os indicadores de gestão educacional das próprias instituições observando-as em dois subconjuntos: o Grupo A, contendo instituições com maior atuação no ensino da pós-graduação e na pesquisa (28 instituições); e um Grupo B, incluindo instituições que tem pouca ou nenhuma atuação no ensino de pós e na graduação (21 instituições). Destarte, utilizando como outputs alunos formados por alunos matriculados e conceito CAPES/MEC para a pós-graduação, e como input o custo corrente por aluno equivalente, número de alunos em tempo integral por docentes equivalentes, número de alunos em tempo integral por funcionários equivalentes e um índice de qualificação do corpo docente, sugeriram que as causas de ineficiência da produção educacional dos IFS variam de acordo com o grupo de análise. No Grupo A, o elevado número de alunos por professores e o aumento do custo por aluno foram causas de ineficiência. Já para o Grupo B, o elevado número de alunos por professores e por funcionários e o índice de qualificação do corpo docente foram os fatores que mais comprometeram a eficiência.

Em relação à literatura especializada, este trabalho complementa a discussão sobre a produtividade relativa na oferta de serviços de educação superior, ao desenvolver uma análise de eficiência direcionada para os departamentos de economia de instituições de ensino superior no Brasil. Ademais, metodologicamente foi feito uma avanço na literatura da área, no sentido de usar um modelo de fronteira não paramétrica com dados em painel e correção bootstrap, bem como fazendo um segundo estágio para verificar como as diferenças nos resultados de eficiência técnica dos departamentos podem ser induzidas por fatores atribuíveis ao próprio aluno.

\section{Metodologia}

Considerando o objetivo deste estudo, ele é desenvolvido em duas etapas. $\mathrm{Na}$ primeira, a abordagem DEA sequencial com bootstrap é utilizada para o cálculo da eficiência dos departamentos de economia do Brasil. Por sua vez, na segunda etapa, emprega-se um modelo de regressão linear com dados em painel para investigar que fatores estão associados às diferenças de eficiência entre as unidades departamentais.

\subsection{Medida de eficiência dos departamentos de economia}

Conforme destaca Maddena et al. (1997), a medição do desempenho organizacional, por meio de sua eficiência, é uma parte essencial da implementação, monitoramento e avaliação do processo produtivo de uma unidade tomadora de decisão (decision making unit, DMU). Em termos da teoria microeconômica, a definição e cálculo de eficiência requer a determinação da função de produção para verificar as melhores práticas produtivas e tecnologicamente factíveis.

Nesse contexto, a abordagem DEA, introduzida por Charnes et al. (1978) e Banker et al. (1984), vem sendo amplamente utilizada em diferentes áreas, 
incluindo as análises acerca do desempenho da oferta dos serviços educacionais de nível superior, tal como verificado na revisão da literatura deste estudo. De acordo com Bogetoft \& Otto (2011), o uso dessa abordagem se deve, em especial, a sua flexibilidade da forma funcional da fronteira de produção, utilização de múltiplos insumos e produtos, poucas hipóteses sobre o comportamento dos dados, uso de variáveis com diferentes unidades de medidas e identificação das unidades de referência (benchmarking) para cada DMU ineficiente.

Na hipótese de múltiplos insumos e produtos, a DEA, por meio de programação matemática linear, estabelece pesos considerando o conjunto de dados disponíveis, através dos quais a performance das unidades da própria amostra delimita os critérios de avaliação. A DEA para múltiplos insumos e produtos trabalha com variáveis agrupadas em vetores: $y=\left(y_{1}, y_{2}, \ldots, y_{\mathrm{J}}\right)$ para os produtos (outputs); $x=\left(x_{1}, x_{2}, \ldots, x_{I}\right)$ para os insumos (inputs).

Para conceituar formalmente a mensuração de eficiência na provisão dos serviços de educação superior, são consideradas as seguintes hipóteses: existem $n$ planos de produção dos serviços educacionais $(k=1, \ldots, n)$ em dado período de tempo $t$. Esses planos de produção combinam $i=1, \ldots, I$ insumos $x_{i}^{k}=\left(x_{1}^{k}, \ldots, x_{I}^{k}\right)$, para produzir $j=1, \ldots, J$ produtos $\mathbf{y}_{j}^{k}=\left(y_{1}^{k}, \ldots, y_{J}^{k}\right)$. Baseado nos trabalhos de Maddena et al. (1997), Belloni (2000), Halkos et al. (2012), a função de produção deste estudo usa os recursos humanos e carga horária do curso de graduação como insumos, e publicações, qualidade do curso de graduação e alunos concluintes de graduação e pós-graduação como medidas de produtos ${ }^{3}$. Vale ressaltar que nesse estudo a DMU é definida pela gestão do departamento de economia das IES brasileiras, o que inclui a oferta dos cursos de graduação e pós-graduação.

A presença da dimensão tempo nos dados referentes aos insumos e aos resultados educacionais permitem uma avaliação mais robusta da eficiência em termos de desempenho organizacional (Färe et al. 1994, Tulkens \& Vanden Eeckaut 1995, Färe \& Grosskopf 1996). Dessa maneira, este trabalho propõe o uso da fronteira temporal de eficiência de forma sequencial, aproveitando-se da estrutura de dados em painel para avaliar a performance dos departamentos de economia. A dependência temporal dos escores de eficiência, incorporada pela fronteira sequencial, baseia-se na suposição de que desempenhos auferidos no passado ainda são factíveis (replicáveis) no presente, excluindo a possibilidade de retrocesso técnico na função de produção. A título de exemplo, no caso deste estudo, possíveis reduções de eficiência no tempo são atribuídas ao gerenciamento departamental, à reputação da instituição e/ou a fatores exógenos (não controláveis pela DMU), como indicadores de atratividade do mercado de trabalho para o economista na região ${ }^{4}$, e não a pioras da tecnologia educacional.

De acordo com Tulkens \& Vanden Eeckaut (1995), o conjunto de produção de referência $(\mathrm{CPR})$ para uma dada DMU pode ser representado pela Equação (1).

$$
\Gamma_{o}=\left\{\left(x^{k}, y^{k}\right) \mid x^{k} \in \mathbb{R}_{+}^{I}, y^{k} \in \mathbb{R}_{+}^{J}, k=1, \ldots, n\right\},
$$

Onde $\Gamma_{o}$ é o conjunto total dos dados; $x$ é o vetor de inputs e $y$ é o vetor de outputs; $n$ é o número total de planos de produções observados; $\Gamma\left(\Gamma_{o}\right)$ é o CPR,

\footnotetext{
${ }^{3}$ A descrição detalhada dos vetores $x$ e $y$ é feita na próxima seção (ver Tabela 2).

${ }^{4}$ Fator esse que pode afetar a demanda dos cursos.
} 
construído a partir de $\Gamma_{o}$.

Considerando a disponibilidade de dados em série de tempo, os $n$ planos de produção podem ser avaliados por meio da Equação (2).

$$
\Gamma_{o}^{K T}=\left\{\left(x^{k t}, y^{k t}\right) \mid x^{k t} \in \mathbb{R}_{+}^{I}, y^{k t} \in \mathbb{R}_{+}^{J}, k=1, \ldots, n, t=1, \ldots, m\right\},
$$

Onde $K, T$ referem-se, respectivamente, ao conjunto de DMUs e de períodos.

Nesse cenário, o cálculo da fronteira sequencial requer uma CPR para cada período, usando as observações do ponto no tempo $\gamma=1$ até $\gamma=t$. Assim, o subconjunto de referência que deve ser considerado para fins da estimação do escore de eficiência é selecionado para $m$ sucessivos CPR sequenciais, de modo que: $\Gamma_{o}^{K(1, t)}=\cup_{\gamma=1}^{t} \Gamma_{o}^{k \gamma}$ e $\Gamma_{o}^{K(1, t)}=\left\{\left(x^{k \gamma}, y^{k \gamma}\right) \mid k=1, \ldots, n, \gamma=1, \ldots, t\right\}$, com $t=1, \ldots, m$.

O cálculo do nível de eficiência técnica pela DEA (com dados de corte ou com dados em painel) mensura o desempenho relativo de unidades organizacionais semelhantes, ao ponderar a razão entre produtos e insumos, gerando um único indicador de performance para cada DMU.

Não obstante, a literatura especializada, como Simar \& Wilson $(1998,2000)$ e Simar \& Wilson (2008), aponta que esses escores "determinísticos" e relativos de eficiência são muito sensíveis a observações atípicas e a pequenas variações na amostra. A partir de $B$ reamostragens, o escore de eficiência $(\theta)$ pode ser calculado $B$ vezes, provendo um estimador $\hat{\theta}_{b}^{k t *}, \operatorname{com} b=1, \ldots, B$, o que permite o desenvolvimento de uma distribuição empírica das estimativas de eficiência para cada DMU e o cálculo de um escore de eficiência com correção de viés $\left(\theta_{b c}\right)$. As Equações 3 e 4 mostram as especificações, de acordo com Simar \& Wilson (2008), da estimativa do $\theta_{b c}$ e de sua variância para a DMU $k$ no período $t$.

$$
\begin{gathered}
\hat{\theta}_{b c}^{k t}=\hat{\theta}^{k t}-\operatorname{viés}_{B}^{k t}\left(\hat{\theta}^{k t}\right)=2 \hat{\theta}^{k t}-B^{-1} \sum_{b=1}^{B} \hat{\theta}_{b}^{k t *}, \\
\hat{\sigma}_{k t}^{2}=B^{-1} \sum_{b=1}^{B}\left[\hat{\theta}_{b}^{k t *}-B^{-1} \sum_{b=1}^{B} \hat{\theta}_{b}^{k t *}\right] .
\end{gathered}
$$

Trabalhos como Johnes $(2006 a, b)$, Halkos et al. (2012), aplicados a avaliação do desempenho do ensino superior, fazem a correção de possíveis vieses das estimativas de eficiência por meio de bootstrap, bem como sugerem que essa abordagem permite um melhor ranqueamento de desempenho, por estabelecer intervalos de confiança das medidas de eficiência e, assim, assegura uma identificação com diferenças estatísticas de resultados entre cada DMU.

Nesse contexto, esta pesquisa integra a extensão da abordagem DEA-S com o procedimento bootstrap de reamostragem para avaliar a eficiência dos departamentos de economia das instituições públicas e privadas de ensino superior no Brasil, considerando 1.000 replicações boostrap e um nível de significância de 5\%. Como estão incluídas na análise instituições públicas, que apresentam certas amarras legais para reduzir o emprego de recursos humanos, os cálculos de eficiência são orientados para o produto.

\subsection{Eficiência condicionada}

Dada à heterogeneidade entre os diferentes departamentos de economia em termos de fatores sociais, econômicos, demográficos e regionais, torna-se rele- 
vante uma análise de segundo estágio acerca do desempenho dessas unidades avaliadas, especialmente condicionando os resultados de eficiência aos atributos dos alunos.

Nos estudos de Joumady \& Ris (2005) e Johnes (2006b), para o caso da Europa, foram incluídas variáveis referentes aos ingressantes dos cursos, como a nota de entrada, na função de produção educacional. Segundo esses autores, tal medida se faz importante para uma melhor avaliação do desempenho organizacional de um curso ou de uma instituição de ensino, dada o papel da qualidade do aluno na função de produção. Cursos que atraem alunos com maiores níveis de habilidades cognitivas (medida captada pela nota de entrada) tendem a ter melhor rendimento acadêmico, o que aumentaria o nível de eficiência da DMU.

Dessa forma, considerando a indisponibilidade de dados sobre a nota de entrada dos discentes nos períodos em análise, foi incluído no modelo de regressão variáveis relacionadas à valorização profissional ${ }^{5}$ (Bartalotti \& Menezes Filho 2007) e à reputação da instituição (Walsh et al. 2017) na época da escolha do curso, como proxies para a qualidade do discente. A hipótese é que boas condições do mercado de trabalho, representada por melhores salários, e instituições com maior reputação acadêmica atrairiam uma demanda mais qualificada. Ademais, em uma das especificações do modelo, incluiu-se a nota do ENADE referente às questões de formação geral como uma proxy do estoque de habilidade cognitiva dos discentes não trabalhadas diretamente (como conteúdo específico) durante o curso de Ciências Econômicas.

Para tanto, considere-se o seguinte modelo de regressão linear com efeitos fixos para a estimação condicional de escores de eficiência ${ }^{6}$ :

$$
\theta_{b c, i t}=\mathbf{L}_{i t-4} \boldsymbol{\Gamma}+\mathbf{z}_{i t} \beta+\mu_{i}+\varepsilon_{i t},
$$

Onde $\theta_{b c, i t}$ é o escore de eficiência da DMU $i$ no período $t ; \mathbf{L}_{i t-4}$ representa o vetor composto por variáveis que medem a qualidade do corpo discente na entrada do curso $(t-4)$, visto que esse período corresponde, em média, a duração de um curso de economia no país; $\mathbf{z}_{i t}$ é um vetor de outras características observadas (background socioeconômico dos discentes e atributos das IES) que potencialmente discriminam os referidos escores, que são melhor detalhadas na próxima seção; $\Gamma$ e $\beta$ são vetores de parâmetros; $\mu_{i}$ é um vetor de características não observadas entre as DMUs constante no tempo; $\varepsilon_{i t}$ é um termo randômico normalmente distribuído com média zero e variância constante e cada DMU $i=1,2, \cdots, n$ é observada no período $t=1,2, \cdots, T$.

Conforme Wooldridge (2010), a estimação da Equação (5) pode ser feita por Mínimos Quadrados Ordinários (MQO) considerando a seguinte equação em diferenças (desvio da equação com médias das variáveis no tempo - transformação por dentro):

$$
\Delta \theta_{b c, i t}=\Delta \mathbf{L}_{i t-4} \Gamma+\Delta \mathbf{z}_{i t} \beta+\Delta \varepsilon_{i t},
$$

\footnotetext{
${ }^{5}$ Conforme salientam Betts (1996), Montmarquette et al. (2002) e Bartalotti \& Menezes Filho (2007), a escolha por uma profissão é função das expectativas dos indivíduos quanto à qualidade da inserção ocupacional no futuro. Desse modo, indivíduos mais hábeis tendem a demandar cursos que permitem uma formação profissional com maiores rendimentos esperados.

${ }^{6}$ Como a variável dependente do modelo é o índice de eficiência corrigido de viés, não se tem a questão de variável censurada à direita e, assim, para o presente caso não se faz necessário o uso de modelo de regressão censurada, como o Tobit.
} 
Onde $\Delta \theta_{b c, i t} \equiv\left(\theta_{b c, i t}-\bar{\theta}_{b c, i}\right) ; \Delta \mathbf{L}_{i t-4} \equiv\left(\mathbf{L}_{i t-4}-\overline{\mathbf{L}}_{i}\right) ; \Delta \mathbf{z}_{i t} \equiv\left(\mathbf{z}_{i t}-\overline{\mathbf{z}}_{i}\right) ; \Delta \varepsilon_{i t} \equiv$ $\left(\varepsilon_{i t}-\bar{\varepsilon}_{i}\right) ; \bar{\theta}_{i}=T_{i}^{-1} \sum_{t=1}^{T_{i}} \theta_{i t}, \overline{\mathbf{L}}_{i}=T_{i}^{-1} \sum_{t=1}^{T_{i}} \mathbf{L}_{i t-4}, \overline{\mathbf{z}}_{i}=T_{i}^{-1} \sum_{t=1}^{T_{i}} \mathbf{z}_{i t}$ e $\bar{\varepsilon}_{i}=T_{i}^{-1} \sum_{t=1}^{T_{i}} \varepsilon_{i t}$, são médias para cada DMU $i$ no tempo no tocante ao escore de eficiência, variáveis de controle e termo randômico, respectivamente.

Portanto, o estimador de efeitos fixos (Equação (6)) elimina o efeito de variáveis não observadas invariantes no tempo $\left(\mu_{i}\right)$ e permite a obtenção de parâmetros consistentes.

\section{Dados}

A construção da base de dados desta pesquisa envolveu o cruzamento de informações de diversas fontes, a saber: microdados do Censo da Educação Superior (CES) e do Exame Nacional de Desempenho dos Estudantes (ENADE) do Instituto Nacional de Estudos e Pesquisas Educacionais Anísio Teixeira (INEP), microdados do Censo dos Diretórios dos Grupos de Pesquisa (DGP) do Conselho Nacional de Desenvolvimento Científico e Tecnológico (CNPq), Relatórios de Avaliações Trienais dos Cursos de Pós-Graduação (RAT) da Coordenação de Aperfeiçoamento de Pessoal de Nível Superior (CAPES) e microdados da Relação Anual de Informações Sociais (RAIS) do Ministério do Trabalho e Emprego (MTE). A periodicidade do estudo definida nos anos 2009 e 2012 se deve ao fato das diferentes bases de dados usadas só permitirem o cruzamento sem grandes perdas amostrais a partir de 2009 e a obtenção de dados com identificação do código docente para o CES $^{7}$ de 2009 e 2012, bem como os dados do ENADE, do RAT e do DGP definem o intervalo trienal da análise.

Tendo como parâmetro a literatura da área (Maddena et al. 1997, Belloni 2000, Avkiran 2011), o vetor de inputs é composto pelo recurso primário para a produção dos departamentos de economia, que é o número de docentes, já que a formação do economista é mais intensiva em recursos humanos do que outras formações (como Biologia, Química, Medicina etc.) que requerem mais recursos materiais (equipamentos, medicamentos, produtos químicos, entre outros). Isso também é justificável pela indisponibilidade de dados para mensurar os recursos financeiros e de capital especificamente empregados por cada departamento. Ademais, a separação dos docentes em dois grupos de formação - com doutorado e demais formações (graduação, especialização ou mestrado) - captura possíveis diferenças nos custos departamentais, visto que a titulação é um dos componentes principais para diferenciação salarial. Em termos gerais, os insumos utilizados buscam espelhar o custo dos departamentos a partir da carga horária e dos recursos humanos.

Baseando-se em Worthington \& Lee (2008), a carga horária do curso de graduação foi considerada como input, medindo o comprometimento dos insumos humanos para às atividades de ensino, assim como cursos com maior carga horária são relativamente mais custosos para a instituição (consumo de energia elétrica, custo de oportunidade dos alunos e dos docentes etc. $)^{8}$.

\footnotetext{
${ }^{7} \mathrm{Na}$ base de dados do CES aberta (disponível no sítio do INEP), o código docente não está disponível, o que impossibilita identificar o quantitativo de professores por curso. Dessa forma, uma tabela auxiliar com tal código foi obtida através da Lei de Acesso à Informação junto ao INEP para 2009 e 2012.

${ }^{8}$ A carga horária do curso de economia estabelecida por meio da Resolução no 2 (18/06/2007) da Câmara de Educação Superior do Conselho Nacional de Educação, que dispõe sobre cursos
} 
O vetor de outputs, como adotado na maior parte das pesquisas internacionais (Maddena et al. 1997, Belloni 2000, Kao \& Hung 2008, Aziz et al. 2013), é formado por medidas relacionadas ao ensino, conclusão e qualidade do curso de graduação, e à pesquisa, esta última sendo mensurada pela quantidade de publicação em periódicos nacionais e internacionais. Ressalta-se que as variáveis usadas no cálculo do nível de eficiência estão medidas, preferencialmente, em nível (como o quantitativo de docentes, concluintes e publicações), a fim de estimar a eficiência de escala dos departamentos.

A Tabela 2 apresenta de forma sumarizada as variáveis usadas em cada um dos dois estágios deste estudo por período e por fonte de origem dos dados.

As informações relacionadas ao número de concluintes da pós-graduação stricto sensu foram calculadas a partir do número de teses e dissertações defendidas no acumulado do triênio de avaliação da CAPES $^{9}$, isto é, de 2007 a 2009 e de 2010 a 2012. O quantitativo da produção em periódicos foi levantado usando os dados censitários dos DGP no CNPq, por meio dos quais contou-se o número de artigos dos pesquisadores cadastrados nos grupos de pesquisas da área de economia vinculados às instituições de ensino superior de um dado município $^{10}$.

Conforme apresentado por Novaes (2008), existe uma elevada ineficiência no sistema de pareceres nos periódicos em economia, com um tempo médio de 20 meses entre a submissão e o aceite nos principais periódicos internacionais: American Economic Review, Econometrica, Journal of Political Economy e Review of Economic Studies. Considerando que esse processo ineficiente de revisão também seja recorrente entre os periódicos nacionais e visto que $76 \%$ da produção acadêmica no censo do DGP está concentrada no país, utilizouse a informação das publicações com um descompasso temporal de dois anos $(t+2)$.

A Tabela A.1 no apêndice do trabalho reporta as estatísticas descritivas das variáveis explicativas utilizadas na etapa de eficiência condicional. A amostra de departamentos de economia usada nesta pesquisa foi de 163 DMUs, em 2009, e 152 DMUs, em 2012, tendo em conta os seguintes filtros: cursos de economia classificados pelo código da Organização para a Cooperação e Desenvolvimento Econômico (OCDE), 314E02; cursos que possuam pelo menos um discente concluinte da graduação, para garantir um tempo mínimo de funcionamento para formação de uma primeira turma (importante, sobretudo, para cursos novos). Esses valores representam, respectivamente, 63,4\% e $61,0 \%$ do universo total de departamentos na área. De forma geral, as estatísticas descritivas apontam que os departamentos de economia possuem, em média, 40 anos de existência, concentram-se na região Sudeste do país e são providos em sua maior parte em instituições privadas, com alunos em sua grande maioria estudando no período noturno. Entre 2009 e 2012, as variáveis que apresentaram mudanças significativas, a pelo menos $5 \%$, foram o percentual de IES da rede pública ofertantes de cursos de economia (aumento

\footnotetext{
de graduação na modalidade presencial e estipula apenas limiares mínimos. Dessa forma, como exposto na Tabela 2, o input carga horária apresenta uma variabilidade de 278 horas no ano de 2012, com um valor mínimo de 2.460 horas, na Universidade Federal do Rio Grande do Sul (UFRGS), e um valor máximo de 4.932 horas, na Faculdade de Campinas (FACAMP).

${ }^{9}$ Nos relatórios de avaliações da CAPES, essa informação está agregada para o triênio, o que impossibilita a contagem para anos específicos do triênio avaliado.

${ }^{10}$ Para evitar dupla contagem intra-instituição, os dados foram filtrados pelo código de identificação do Currículo Lattes de pesquisadores que estavam inseridos em mais de um grupo de pesquisa dentro da mesma instituição.
} 
Tabela 2: Definição das variáveis de input e output para o DEA e variáveis para o segundo estágio da pesquisa

\begin{tabular}{|c|c|c|c|c|}
\hline Tipo & Variável & Fonte & \multicolumn{2}{|l|}{ Período } \\
\hline \multicolumn{5}{|c|}{ I - Eficiência incondicional } \\
\hline \multirow[t]{3}{*}{ Inputs } & $\begin{array}{l}\text { Carga-horária do curso de graduação } \\
\left(x_{1}\right)\end{array}$ & CES/INEP & 2009 e 2012 & \\
\hline & Número de docentes com doutorado $\left(x_{2}\right)$ & CES/INEP & 2009 e 2012 & \\
\hline & $\begin{array}{l}\text { Número de docentes com outras forma- } \\
\text { ções }\left(x_{3}\right)\end{array}$ & CES/INEP & 2009 e 2012 & \\
\hline \multirow[t]{4}{*}{ Outputs } & $\begin{array}{l}\text { Número de concluintes na graduação } \\
\left(y_{1}\right)\end{array}$ & CES/INEP & 2009 e 2012 & \\
\hline & $\begin{array}{l}\text { Média da nota do ENADE dos concluin- } \\
\text { tes da graduação }\left(y_{2}\right)\end{array}$ & ENADE/INEP & 2009 e 2012 & \\
\hline & $\begin{array}{l}\text { Número de concluintes na pós- } \\
\text { graduação stricto sensu }\left(y_{3}\right)\end{array}$ & RAT/CAPES & $\begin{array}{l}2007-2009 \text { e } \\
2012\end{array}$ & 2010- \\
\hline & $\begin{array}{l}\text { Número de publicações em periódicos } \\
\text { nacionais e internacionais }\left(y_{4}\right)\end{array}$ & $\mathrm{DGP} / \mathrm{CNPq}$ & 2011 e 2014 & \\
\hline \multicolumn{5}{|c|}{ II - Eficiência condicional } \\
\hline & Percentual de alunos da cor negra & CES/INEP & 2009 e 2012 & \\
\hline & $\begin{array}{l}\text { Percentual de alunos que recebem apoio } \\
\text { social da instituição }\end{array}$ & CES/INEP & 2009 e 2012 & \\
\hline & $\begin{array}{l}\text { Percentual de alunos matriculados no } \\
\text { turno da noite }\end{array}$ & CES/INEP & 2009 e 2012 & \\
\hline & $\begin{array}{l}\text { Percentual de pais dos alunos com en- } \\
\text { sino primário incompleto }\end{array}$ & ENADE/INEP & 2009 e 2012 & \\
\hline & $\begin{array}{l}\text { Percentual de mães dos alunos com en- } \\
\text { sino primário incompleto }\end{array}$ & ENADE/INEP & 2009 e 2012 & \\
\hline & $\begin{array}{l}\text { Percentual de alunos com alta renda fa- } \\
\text { miliar ( } 6 \text { salários mínimos ou mais) }\end{array}$ & ENADE/INEP & 2009 e 2012 & \\
\hline & $\begin{array}{l}\text { Percentual de alunos que estudaram o } \\
\text { ensino médio em escola pública }\end{array}$ & ENADE/INEP & 2009 e 2012 & \\
\hline & $\begin{array}{l}\text { Salário do economista relativo a outras } \\
\text { profissões de ensino superior }\end{array}$ & RAIS/MTE & 2005 e 2008 & \\
\hline & Salário-hora do economista & RAIS/MTE & 2005 e 2008 & \\
\hline & $\begin{array}{l}\text { Taxa de participação do economista na } \\
\text { força de trabalho formal }\end{array}$ & RAIS/MTE & 2005 e 2008 & \\
\hline & $\begin{array}{l}\text { Reputação da IES (Índice Geral de Cur- } \\
\text { sos - IGC) }\end{array}$ & INEP & $\begin{array}{l}2005-2007 \quad \text { e } \\
2010\end{array}$ & 2008- \\
\hline & $\begin{array}{l}\text { Nota do ENADE: proficiência na forma- } \\
\text { ção geral }\end{array}$ & ENADE/INEP & 2009 e 2012 & \\
\hline & Média da idade do corpo docente & CES/INEP & 2009 e 2012 & \\
\hline & $\begin{array}{l}\text { Percentual de docentes com bolsa de pes- } \\
\text { quisa }\end{array}$ & CES/INEP & 2009 e 2012 & \\
\hline & $\begin{array}{l}\text { Razão entre total de docente e total ser- } \\
\text { vidores técnicos da IES }\end{array}$ & CES/INEP & 2009 e 2012 & \\
\hline & $\begin{array}{l}\text { Percentual de alunos que acham a infra- } \\
\text { estrutura inadequada do curso }\end{array}$ & ENADE/INEP & 2009 e 2012 & \\
\hline & Total de alunos ingressantes na IES & CES/INEP & 2009 e 2012 & \\
\hline & $\begin{array}{l}\text { Tempo de criação do curso de graduação } \\
\text { em economia* }\end{array}$ & CES/INEP & 2009 e 2012 & \\
\hline & $\begin{array}{l}\text { Variável binária para instituição } \\
\text { pública* }\end{array}$ & CES/INEP & 2009 e 2012 & \\
\hline & $\begin{array}{l}\text { Variável binária de localização do depar- } \\
\text { tamento na capital estadual }\end{array}$ & CES/INEP & 2009 e 2012 & \\
\hline & $\begin{array}{l}\text { Variáveis binárias de localização em } \\
\text { grandes regiões* }\end{array}$ & CES/INEP & 2009 e 2012 & \\
\hline
\end{tabular}

Fonte: Elaboração própria.

Nota: *Variáveis usadas apenas nos modelos sem efeito fixo do departamento. 
de 23,6 pontos percentuais), maior escolaridade dos pais e das mães dos alunos, maior taxa de docentes com bolsas de pesquisa e uma melhoria no Índice Geral de Cursos (IGC) em 7,7\%, na média. Destaca-se que o IGC é usado como uma proxy do nível de reputação acadêmica da IES vinculada ao curso de economia na época da escolha do discente em relação ao curso e a IES. O IGC é um indicador usado pelo INEP como uma medida sintética da performance geral de todos os cursos de graduação, pós-graduação e produção científica das instituições de ensino.

Em relação aos indicadores de mercado de trabalho, a variável salário-hora do economista foi calculada considerando a média salarial dos trabalhadores formais com os seguintes códigos brasileiros de ocupação (CBO) de 2002: 251210 - Economista agroindustrial; 251205 - Economista; 251220 - Economista industrial; 251225 - Economista do setor público; 251230 - Economista ambiental; 251235 - Economista regional e urbano; 251215 - Economista financeiro; 203510 - Pesquisador em Economia; 234805 - Professor de Economia. Embora o economista possa ter inserção ocupacional em outras áreas, os CBOs supracitados são aqueles em que existem uma maior propensão de um formado em Ciências Econômicas estar exercendo a função. Adicionalmente, a profissão do economista é regulamentada pelo Conselho Federal de Economia, tendo como código-chave 2512 do CBO.

A Tabela 3 apresenta as estatísticas descritivas das variáveis usadas com inputs e outputs na função de produção educacional dos departamentos de economia. Conforme as estatísticas descritivas das variáveis para o período mais recente, os departamentos de economia, em média, são compostos por um total de 43 docentes (sendo 20 deles com a formação de doutor), os cursos de graduação têm uma carga horária de pouco mais de 3.100 horas com um desvio-padrão de 282 horas. Quanto aos produtos, verifica-se que em 2012, a quantidade de concluintes na graduação e na pós-graduação foi, respectivamente, de 34 e 15 discentes, com um desempenho médio no ENADE de 31 (escala de 0 a 100) e 201 publicações em periódicos nacionais e internacionais no acumulado do triênio (2010-2012). Em termos de evolução, nota-se um crescimento no tamanho dos departamentos no período de 2009 a 2012, em $22,9 \%$ no número total de docentes, com destaque para a participação dos professores com doutorado. O maior departamento de economia no Brasil, em termos de professores, em 2009 era a Universidade de Brasília (UNB), que também apresentava a maior nota do ENADE e a maior quantidade de publicações. Já em 2012, a UFRJ deteve o maior número de professores, enquanto que a Pontifícia Universidade Católica de São Paulo (PUCSP) se destacou em termos de concluintes da graduação e a Universidade Federal do Ceará (UFC) foi destaque na formação de alunos pós-graduados.

Como ressalta Sarkis (2006), a abordagem DEA presume que os vetores de produtos e de insumos sejam estritamente positivos. Assim, seguindo a recomendação do referido autor, foram adicionadas uma constante arbitrária (neste caso uma constante igual a uma unidade) para todas as variáveis que apresentavam informações nulas ${ }^{11}$, como docentes com doutorado $\left(x_{2}\right)$, número de concluintes da pós-graduação $\left(y_{3}\right)$ e produção em periódicos $\left(y_{4}\right)$.

\footnotetext{
${ }^{11}$ Essa estratégia não impõe mudanças no ranqueamento (Sarkis 2006).
} 
Tabela 3: Estatísticas descritivas para as variáveis de input e output

\begin{tabular}{|c|c|c|c|c|c|}
\hline & Estatística & Carga-horária $^{*} x_{1}$ & $\begin{array}{c}\text { INPUTS } \\
\text { Docentes com Doutorado } x_{2}\end{array}$ & Docentes com outras formações $x_{3}$ & \\
\hline \multirow[t]{7}{*}{2009} & Observações & 163,00 & 163,00 & 163,00 & \\
\hline & Mínimo & $2.460,00$ & 0,00 & 3,00 & \\
\hline & & [UFRGS] & {$[\mathrm{L} 1]$} & [IAESUP] & \\
\hline & Máximo & $4.932,00$ & 178,00 & 89,00 & \\
\hline & & (FACAMP) & (UNB) & (UNB) & \\
\hline & Média & $3.102,00$ & 13,00 & 22,00 & \\
\hline & $\mathrm{DP}$ & 282,00 & 24,00 & 16,00 & \\
\hline \multirow[t]{9}{*}{2012} & Observações & 152,00 & 152,00 & 152,00 & \\
\hline & Mínimo & $2.460,00$ & 0,00 & 3,00 & \\
\hline & & [UFRGS] & {$[\mathrm{L} 2]$} & [FICS] & \\
\hline & Máximo & $4.932,00$ & 257,00 & 152,00 & \\
\hline & & (FACAMP) & (UFRRJ) & (UFRRJ) & \\
\hline & Média & $3.116,00$ & 20,00 & 23,00 & \\
\hline & DP & 278,00 & 30,00 & 18,00 & \\
\hline & & & OUTPUTS & & \\
\hline & & Concluintes na Graduação $y_{1}$ & Nota do ENADE $y_{2}$ & Concluintes na Pós-Graduação $y_{3}$ & Publicações em periódicos $y_{4}$ \\
\hline \multirow[t]{7}{*}{2009} & Observações & 163,00 & 163,00 & 163,00 & 163,00 \\
\hline & Mínimo & 3,00 & 18,00 & 0,00 & 0,00 \\
\hline & & [L3] & [IESAM] & {$[\mathrm{L} 5]$} & [L6] \\
\hline & Máximo & 218,00 & 63,00 & 208,00 & $4.116,00$ \\
\hline & & (UEL) & (UNB) & (UFC) & (UNB) \\
\hline & Média & 38,00 & 38,00 & 12,00 & 168,00 \\
\hline & DP & 36,00 & 8,00 & 32,00 & 457,00 \\
\hline \multirow[t]{7}{*}{2012} & Observações & 152,00 & 152,00 & 152,00 & \\
\hline & Mínimo & 3,00 & 5,00 & 0,00 & 0,00 \\
\hline & & {$[\mathrm{L} 4]$} & [UEFS] & [UFSM] & UEFS \\
\hline & Máximo & 237,00 & 52,00 & 273,00 & $3.738,00$ \\
\hline & & (PUCSP) & (EESP) & (UFC) & (UNB) \\
\hline & Média & 34,00 & 31,00 & 15,00 & 201,00 \\
\hline & DP & 32,00 & 5,00 & 40,00 & 482,00 \\
\hline
\end{tabular}

Legenda: DP = Desvio-Padrão; *em horas; entre parênteses, sigla da IES com mínimo valor no indicador; entre colchetes, a IES com máximo valor.

${ }^{a}$ L1 = FANORPI, IAESUP, FAHOR, UNIFAE, UNIUV, UNICRUZ, FIFE, FARES, UNIFEG, UNIFAI, UNESC, FASAR, UCP, CEAP, FTC, CESMAC, FAVIP, FCHE,

UVV, UEMS, FECEA, FIP, UNINORTE; L2 = ISCA, FICS, UVV, ESAMC, ALFA, FECEA, FIP, UNEMAT, FACIMP, FEST; L3 = ALFA, FACAPE, UNESC; L4 =

UNEB, UFGD, FRB; L5 = UFPEL, UFAL, UEL; L6 = UNINOVE, UEFS, PUC-CAMPINAS. 


\section{Resultados}

A Tabela A.2 reporta os principais resultados do modelo DEA de fronteira sequencial para um painel de dados desbalanceado (2009 e 2012), considerando os escores de eficiência técnica com retornos variáveis (denotado também como eficiência técnica pura) com e sem correção de viés por bootstrap ${ }^{12}$. Vale notar que foram empregados três insumos (carga horária do curso de graduação, número de docentes com doutorado, número de docentes com outras formações) e quatro produtos (número de concluintes no curso de graduação, média da nota do ENADE dos concluintes da graduação, número de concluintes na pós-graduação stricto sensu, número de publicações em periódicos nacionais e internacionais). Ademais, os dados estão organizados pelo tipo da IES (privada e pública).

Os resultados indicam uma tendência de redução, estatisticamente significativa a pelo menos $1 \%$, do desempenho médio das unidades departamentais avaliadas no interregno 2009-2012. É possível observar que o nível médio de eficiência varia entre os modelos DEA com e sem correção de viés de 80,3\% a $85,9 \%$, em 2009 , e $64,4 \%$ a $69,8 \%$, em 2012, respectivamente. Em geral, os escores de eficiência produzidos com reamostragem (bootstrap) apresentam médias inferiores àquelas calculadas de forma específica para uma única amostra de dados. Conforme Simar \& Wilson (2008), a correção por bootstrap produz estimadores de eficiência menos sensíveis ao processo de geração dos dados, sendo mais robustos, por exemplo, a problemas com observações atípicas. Nesta pesquisa, a redução de viés, em média, foi de $-7,7 \%$ com IC(viés, $95 \%)=[-8,3 \% ;-7,1 \%]$, em 2009 , e de $-11,1 \%$ com IC(viés, $95 \%)=[-12,1 \%$; $-10,2 \%]$, em 2012.

Ao se comparar os escores de eficiência técnica entre departamentos de IES privadas e de IES públicas constata-se que, em média, não há diferença estatística entre os desempenhos dessas unidades. Por outro lado, quando as DMUs são distribuídas segundo intervalos de eficiência por quartis algumas diferenças chamam atenção. Primeiro, a tendência de piora de práticas produtivas ocorre não apenas na média, mas em toda a distribuição dos departamentos. Nesse aspecto, observa-se que, entre 2009 e 2012, houve uma transição de várias unidades classes de baixa produtividade relativa. Por exemplo, em 2009 havia 71 departamentos na classe de maior eficiência $\left(0,85<\theta_{b c} \leq 0,98\right)$ e 10 unidades na classe de menor desempenho $\left(0,35<\theta_{b c} \leq 0,62\right)$, enquanto em 2012 esses quantitativos passaram para 8 e 68 DMUs, respectivamente. Esse padrão de transição também é observado quando se analisam os departamentos de economia por tipo de IES (privada ou pública), de modo que tais evidências sugerem uma piora na oferta de serviços de ensino e de produção acadêmica na maior parte das DMUs ${ }^{13}$.

Outro dado importante diz respeito à redução observada do total de unidades departamentais ao longo do período estudado. Considerando a amostra

\footnotetext{
${ }^{12} \mathrm{Na}$ Tabela A.2 no Apêndice, encontra-se a lista dos 20 departamentos de economia com maior e menor eficiência, bem como distribuições dos escores de eficiência com e sem correção de viés por bootstrap encontram-se apresentados na Figura A.1.

${ }^{13} \mathrm{O}$ crescimento da demanda por periódicos nacionais e internacionais em conjunto com o maior tempo para aceite de publicações pode ter contribuído para uma tendência de queda no número de publicações. Muito embora, no total, a média de publicações teve um aumento, esse valor na verdade está sendo influenciado pela mudança de composição do quantitativo de departamentos.
} 
Tabela 4: Descrição dos escores de eficiência do modelo DEA sequencial com retornos variáveis (VRS), total e por rede administrativa da IES - 2009 e 2012

\begin{tabular}{|c|c|c|c|c|c|c|}
\hline & \multicolumn{2}{|c|}{ Total } & \multicolumn{2}{|c|}{ IES privada } & \multicolumn{2}{|c|}{ IES pública } \\
\hline & 2009 & 2012 & 2009 & 2012 & 2009 & 2012 \\
\hline $\begin{array}{l}\text { Eficiência técnica pura } \\
\text { média (sem correção) }\end{array}$ & $\begin{array}{l}85,90 \\
(1,03)\end{array}$ & $\begin{array}{l}69,76 \\
(1,27)\end{array}$ & $\begin{array}{l}85,97 \\
(1,17)\end{array}$ & $\begin{array}{r}71,51 \\
(1,66)\end{array}$ & $\begin{array}{l}85,63 \\
(2,13)\end{array}$ & $\begin{array}{l}67,55 \\
(1,96)\end{array}$ \\
\hline média (com correção) & $\begin{array}{l}80,30 \\
(0,86)\end{array}$ & $\begin{array}{l}64,39 \\
(1,03)\end{array}$ & $\begin{array}{l}80,54 \\
(1,00)\end{array}$ & $\begin{array}{l}66,24 \\
(1,34)\end{array}$ & $\begin{array}{l}79,38 \\
(1,68)\end{array}$ & $\begin{array}{l}62,05 \\
(1,58)\end{array}$ \\
\hline $\begin{array}{l}\text { Distribuição por quarti } \\
0,35<\theta_{b c} \leq 0,62\end{array}$ & $\begin{array}{l}10,00 \\
{[6,13]}\end{array}$ & $\begin{array}{r}68,00 \\
{[44,74]}\end{array}$ & $\begin{array}{r}9,00 \\
{[6,98]}\end{array}$ & $\begin{array}{l}36,00 \\
{[42,35]}\end{array}$ & $\begin{array}{c}1,00 \\
{[2,94]}\end{array}$ & $\begin{array}{r}32,00 \\
{[47,76]}\end{array}$ \\
\hline $0,62<\theta_{b c} \leq 0,72$ & $\begin{array}{r}31,00 \\
{[19,02]}\end{array}$ & $\begin{array}{r}48,00 \\
{[31,58]}\end{array}$ & $\begin{array}{r}23,00 \\
{[17,83]}\end{array}$ & $\begin{array}{l}26,00 \\
{[30,59]}\end{array}$ & $\begin{array}{r}8,00 \\
{[23,53]}\end{array}$ & $\begin{array}{r}22,00 \\
{[32,84]}\end{array}$ \\
\hline $0,72<\theta_{b c} \leq 0,85$ & $\begin{array}{l}51,00 \\
{[31,29]}\end{array}$ & $\begin{array}{r}27,00 \\
{[17,76]}\end{array}$ & $\begin{array}{r}40,00 \\
{[31,01]}\end{array}$ & $\begin{array}{l}17,00 \\
{[20,00]}\end{array}$ & $\begin{array}{l}11,00 \\
{[32,35]}\end{array}$ & $\begin{array}{l}10,00 \\
{[14,93]}\end{array}$ \\
\hline $0,85<\theta_{b c} \leq 0,98$ & $\begin{array}{r}71,00 \\
{[43,56]}\end{array}$ & $\begin{array}{c}8,00 \\
{[5,26]}\end{array}$ & $\begin{array}{r}57,00 \\
{[44,19]}\end{array}$ & $\begin{array}{r}6,00 \\
{[7,06]}\end{array}$ & $\begin{array}{r}14,00 \\
{[41,18]}\end{array}$ & $\begin{array}{c}2,00 \\
{[2,99]}\end{array}$ \\
\hline $\begin{array}{l}\text { Eficiência de escala } \\
\text { média (sem correção) }\end{array}$ & $\begin{array}{l}94,36 \\
(0,57)\end{array}$ & $\begin{array}{l}94,77 \\
(0,58)\end{array}$ & $\begin{array}{l}93,86 \\
(0,69)\end{array}$ & $\begin{array}{r}94,90 \\
(0,87)\end{array}$ & $\begin{array}{l}96,25 \\
(0,77)\end{array}$ & $\begin{array}{l}94,60 \\
(0,74)\end{array}$ \\
\hline média (com correção) & $\begin{array}{l}93,75 \\
(0,59)\end{array}$ & $\begin{array}{l}94,08 \\
(0,63)\end{array}$ & $\begin{array}{l}93,34 \\
(0,71)\end{array}$ & $\begin{array}{r}94,35 \\
(0,93)\end{array}$ & $\begin{array}{l}95,30 \\
(0,77)\end{array}$ & $\begin{array}{l}93,75 \\
(0,82)\end{array}$ \\
\hline \multicolumn{7}{|l|}{ Distribuição por escala* } \\
\hline Retorno constante & $\begin{array}{r}23,00 \\
{[14,11]}\end{array}$ & $\begin{array}{l}13,00 \\
{[8,55]}\end{array}$ & $\begin{array}{l}17,00 \\
{[13,18]}\end{array}$ & $\begin{array}{r}7,00 \\
{[8,24]}\end{array}$ & $\begin{array}{r}6,00 \\
{[17,65]}\end{array}$ & $\begin{array}{l}6,00 \\
{[8,96]}\end{array}$ \\
\hline Retorno crescente & $\begin{array}{l}110,00 \\
{[67,48]}\end{array}$ & $\begin{array}{l}111,00 \\
{[73,03]}\end{array}$ & $\begin{array}{r}85,00 \\
{[65,89]}\end{array}$ & $\begin{array}{l}63,00 \\
{[74,12]}\end{array}$ & $\begin{array}{r}25,00 \\
{[73,53]}\end{array}$ & $\begin{array}{r}48,00 \\
{[71,64]}\end{array}$ \\
\hline Retorno decrescente & $\begin{array}{r}30,00 \\
{[18,40]}\end{array}$ & $\begin{array}{r}28,00 \\
{[18,42]}\end{array}$ & $\begin{array}{r}27,00 \\
{[20,93]}\end{array}$ & $\begin{array}{l}15,00 \\
{[17,65]}\end{array}$ & $\begin{array}{c}3,00 \\
{[8,82]}\end{array}$ & $\begin{array}{r}13,00 \\
{[19,40]}\end{array}$ \\
\hline Total de DMUs & 163,00 & 152,00 & 129,00 & 85,00 & 34,00 & 67,00 \\
\hline \multicolumn{7}{|l|}{ Insumos (média) } \\
\hline Carga horária $(\mathrm{mil})\left(x_{1}\right)$ & $\begin{array}{l}3,10 \\
(0,02)\end{array}$ & $\begin{array}{l}3,12 \\
(0,02)\end{array}$ & $\begin{array}{l}3,14 \\
(0,03)\end{array}$ & $\begin{array}{r}3,15 \\
(0,03)\end{array}$ & $\begin{array}{l}2,97 \\
(0,04)\end{array}$ & $\begin{array}{c}3,07 \\
(0,03)\end{array}$ \\
\hline Docentes doutores $\left(x_{2}\right)$ & $\begin{array}{l}14,29 \\
(1,89)\end{array}$ & $\begin{array}{l}20,23 \\
(2,46)\end{array}$ & $\begin{array}{l}8,29 \\
(0,96)\end{array}$ & $\begin{array}{l}11,73 \\
(1,45)\end{array}$ & $\begin{array}{l}37,09 \\
(7,10)\end{array}$ & $\begin{array}{l}31,01 \\
(4,98)\end{array}$ \\
\hline Demais docentes $\left(x_{3}\right)$ & $\begin{array}{l}21,78 \\
(1,24)\end{array}$ & $\begin{array}{l}23,05 \\
(1,50)\end{array}$ & $\begin{array}{l}19,67 \\
(1,20)\end{array}$ & $\begin{array}{l}19,54 \\
(1,46)\end{array}$ & $\begin{array}{l}29,76 \\
(3,50)\end{array}$ & $\begin{array}{l}27,49 \\
(2,77)\end{array}$ \\
\hline \multicolumn{7}{|l|}{ Produtos (média) } \\
\hline Graduados $\left(y_{1}\right)$ & $\begin{array}{l}38,03 \\
(2,79)\end{array}$ & $\begin{array}{l}34,39 \\
(2,61)\end{array}$ & $\begin{array}{l}33,31 \\
(3,14)\end{array}$ & $\begin{array}{c}30,98 \\
(3,89)\end{array}$ & $\begin{array}{l}55,94 \\
(5,16)\end{array}$ & $\begin{array}{l}38,72 \\
(3,23)\end{array}$ \\
\hline Nota ENADE $\left(y_{2}\right)$ & $\begin{array}{l}38,25 \\
(0,63)\end{array}$ & $\begin{array}{l}30,88 \\
(0,44)\end{array}$ & $\begin{array}{l}37,03 \\
(0,66)\end{array}$ & $\begin{array}{l}31,11 \\
(0,52)\end{array}$ & $\begin{array}{l}42,86 \\
(1,44)\end{array}$ & $\begin{array}{l}30,58 \\
(0,75)\end{array}$ \\
\hline Pós-graduados $\left(y_{3}\right)$ & $\begin{array}{l}12,55 \\
(2,51)\end{array}$ & $\begin{array}{l}16,18 \\
(3,25)\end{array}$ & $\begin{array}{c}6,29 \\
(1,82)\end{array}$ & $\begin{array}{c}9,04 \\
(3,10)\end{array}$ & $\begin{array}{l}36,29 \\
(8,80)\end{array}$ & $\begin{array}{l}25,24 \\
(6,08)\end{array}$ \\
\hline Publicações $\left(y_{4}\right)$ & $\begin{array}{c}169,40 \\
(35,80)\end{array}$ & $\begin{array}{c}202,10 \\
(39,10)\end{array}$ & $\begin{array}{c}84,70 \\
(26,30)\end{array}$ & $\begin{array}{l}52,80 \\
(22,60)\end{array}$ & $\begin{array}{l}490,60 \\
(126,40)\end{array}$ & $\begin{array}{c}391,60 \\
(78,30)\end{array}$ \\
\hline
\end{tabular}

Fonte: Elaboração própria.

Nota: Erro-padrão entre parênteses. Distribuição percentual entre colchetes; média com correção refere-se ao escore de eficiência com correção do viés por 1000 replicações bootstrap. *Para identificação do tipo de retorno de escala, foram usados os modelos DEA de fronteira sequencial com retornos constantes, decrescentes e variáveis de escala sem o processo de reamostragem. 
final utilizada nesta pesquisa ${ }^{14}$, enquanto que no ano de 2009 haviam 163 departamentos de economia, em 2012 esse número diminuiu para 152. Em particular, chama atenção a forte redução no tocante à oferta de cursos de economia no âmbito das IES privadas, cujo total de departamentos passou de 129 unidades em 2009 para 85 unidades em 2012 (-34,1\%). Na contramão deste processo, o número de departamentos de economia nas IES públicas passou de 34, em 2009, para 67, em 2012. Tais alterações na composição da oferta dos cursos de economia podem estar associadas às políticas do governo federal no período, como o Programa de Reestruturação e Expansão das Universidades Federais (REUNI) e Programa Universidade para Todos (PROUNI).

O REUNI foi criado por meio do decreto $\mathrm{n}^{\circ} 6.096 / 2007$, tendo iniciado as suas ações em 2008, com destaque para ampliação do número de matrículas, interiorização dos campi e realização de concursos para docentes e técnicos administrativos da rede federal, contando com investimento já em 2008 de $\mathrm{R} \$ 415$ milhões ${ }^{15}$. Dessa maneira, a expansão na oferta de matrículas promovida pelo REUNI, nos primeiros anos do programa, já poderiam gerar impacto nos indicadores de rendimento acadêmico da graduação em 2012 (como uma redução na taxa de conclusão dos cursos, dado o problema de reprovação e evasão dos novos alunos em face às deficiências da educação básica). Ademais, o aumento do quadro de docentes ${ }^{16}$ também gerariam efeitos nos inputs do modelo DEA dos departamentos de economia da rede federal de ensino superior.

Outro programa federal que pode ter exercido influência para alterar a composição da oferta dos cursos de economia no intervalo de tempo considerado na presente pesquisa foi o PROUNI, um programa de concessão de bolsas de estudo para egressos do ensino médio estudarem em instituições privadas de ensino superior. O PROUNI teve início no ano de 2005, com concessão de mais 112 mil bolsas, e uma significativa expansão a partir de 2008, período em que as bolsas concedidas foram superiores a 220 mil por ano ${ }^{17}$. Nesse contexto, o PROUNI ampliou o leque de opções de escolha de cursos e instituições por parte dos alunos, afetando a demanda por vagas no ensino superior e a provisão de vagas, sobretudo, na rede privada ${ }^{18}$. Essas intervenções governamentais no mercado de educação superior podem estar por trás das significativas mudanças nos indicadores de eficiência técnica no curto período de tempo avaliado.

Segundo Ferreira \& Gomes (2009) e Cooper et al. (2011), os escores de eficiência pelo modelo DEA podem ser decompostos em eficiência técnica pura e de escala, possibilitando identificar diferentes fontes de ineficiência. A eficiência de escala se relaciona com o tamanho da operação da DMU, enquanto a

\footnotetext{
${ }^{14}$ Essa tendência observada na amostra final também foi constatada com o universo de departamentos de economia no Brasil, conforme apresentado na introdução.

${ }^{15}$ Informação disponível no sítio do programa, em <http://reuni.mec.gov.br/>.

${ }^{16}$ Segundo Souza et al. (2015), entre 2008 e 2012, foram autorizados quase 22 mil novas vagas docentes na rede federal de ensino.

${ }^{17}$ Dados disponíveis nas estatísticas e dados do programa em $<$ http://prouniportal.mec.gov.br/>.

${ }^{18}$ Considerando o crescimento expressivo de vagas em cursos como Administração, Direito e Enfermagem na rede privada a partir de meados de 2000, o PROUNI (juntamente com outras iniciativas de financiamento estudantil) podem ter estimulado uma substituição de oferta de vagas de economia na rede privada por cursos que tinham maior apelo da demanda dos estudantes. Esse fator pode ser uma explicação para a redução no número de departamentos de economia em IES particulares entre 2009 e 2012.
} 
eficiência técnica pura supõe a comparação por escala similares. Ao se analisar a distribuição dos departamentos de economia conforme o tipo de retorno de escala percebe-se que a maioria das DMUs, tanto em IES privadas $(74 \% \mathrm{em}$ 2012) quanto em IES públicas ( $72 \%$ em 2012), ainda opera em tamanho pequeno (retornos crescentes). Tal evidência sugere que tais unidades poderiam se beneficiar de ganhos de produtividade (redução de custos operacionais) a partir de uma possível expansão de suas escalas. Contudo, esses ganhos seriam limitados, dado que o nível de eficiência de escala (com e sem correção por bootstrap), em média, foi superior a 90\% em 2009 e 2012.

Nesse sentido, medir a eficiência técnica e de escala dos departamentos pode fornecer subsídios para planejamento das DMUs no curto e longo prazo, tendo em vista o redimensionamento do quadro de docentes e geração de incentivos para ampliação dos indicadores de ensino e pesquisa. Conforme o ranqueamento apresentado na Tabela A.2 no Apêndice pelo nível de eficiência técnica com retornos variáveis de escala (conhecida como eficiência técnica pura), nota-se a existência de departamentos com as melhores classificações nesse critério operando com algum grau de ineficiência de escala (seja crescente ou decrescente).

Os dados da Tabela 4 também permitem relacionar o desempenho das DMUs com seus valores médios de inputs e outputs. Por exemplo, considerando médias estatisticamente diferentes, pode-se afirmar que a redução na média de desempenho dos departamentos verificada entre os anos de 2009 e 2012, parece ter sido acompanhada por um ligeiro aumento na média de docentes doutores $(+41,6 \%$ variação média) e forte redução da nota dos graduados no ENADE $(-19,3 \%)$. No caso dos departamentos de IES privadas, se observa um padrão similar, isto é, considerável redução da nota média do ENADE $(-15,9 \%)$ e aumento médio de docentes com doutorado $(+41,5 \%)$. Já nos departamentos vinculados a IES públicas, a piora de desempenho médio se conjuga a uma diminuição significativa da média de graduados $(-30,8 \%)$ e redução da nota do ENADE $(-28,6 \%)$.

No intuito de melhor explorar algumas evidências apresentadas na tabela anterior, a Figura 1 ilustra resultados de estimativas de funções densidades de núcleo para os escores de eficiência técnica das DMUs estudadas comparando os seguintes aspectos: (i) diferenças estatísticas na distribuição de eficiência de unidades departamentais após correção de viés pelo método bootstrap (Figura 1)(a) ; (ii) diferenças de distribuições inter-período (Figura 1)(b); (iii) comparações de distribuições de eficiência entre departamentos de economia de IES privadas e IES públicas por período (Figura 1)(c) e Figura 1)(d). A partir da Figura 1(b), considera-se apenas o índice de eficiência corrigido de viés.

No tocante à correção de viés dos escores de eficiência, os resultados revelam que o uso do método DEA com reamostragem bootstrap, referendado por Simar \& Wilson (2008), produziu uma mudança significativa da distribuição dos escores de eficiência técnica. Em geral, conforme observado na Figura 1, os escores obtidos pelo DEA de fronteira sequencial com reamostragem possuem distribuição menos assimétrica comparada àquela estimada a partir de escores calculados sem o uso de bootstrap.

A Figura 1(b) revela evidências consistentes com os dados apresentados na Tabela 4. Ou seja, há diferenças estatisticamente significativas entre as distribuições estimadas para os períodos de 2009 e 2012 partir da DEA sequencial com bootstrap. Em geral, é possível observar uma maior concentração de 
Figura 1: Comparação entre as distribuições dos escores de eficiência técnica dos departamentos de economia conforme o modelo DEA, o período e o tipo de IES

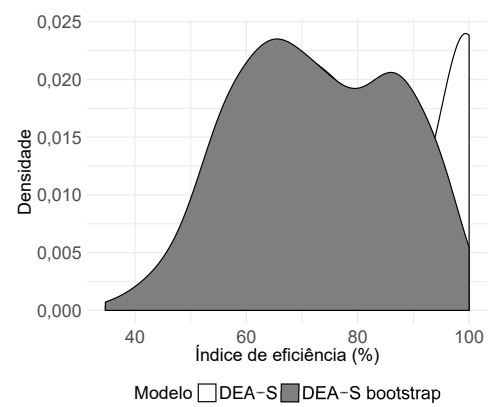

(a) Modelo (2009-2012): $\mathrm{D}=0,25 ; \mathrm{p}=0,00$

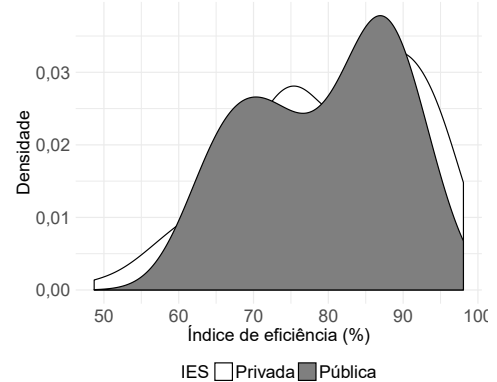

(c) IES 2009: $\mathrm{D}=0,15 ; \mathrm{p}=0,51$

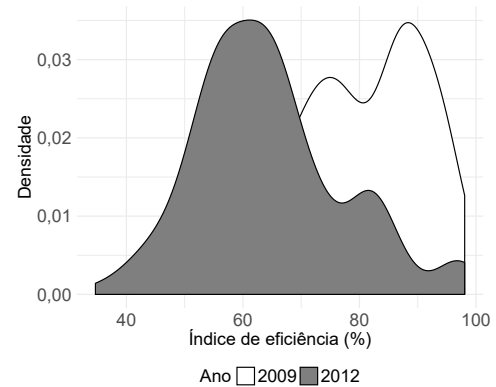

(b) Entre 2009 e 2012: $D=0,56 ; p=0,00$

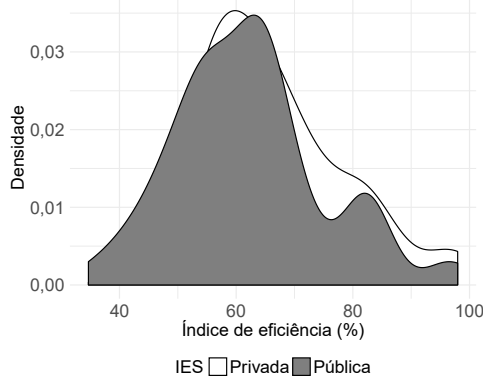

(d) IES 2012: $\mathrm{D}=0,15 ; \mathrm{p}=0,51$

Fonte: Elaboração própria. $D$ é a estatística do teste de Kolmogorov-Smirnov de igualdade entre duas distribuições contínuas; $p$ refere-se ao $\mathrm{p}$-valor.

massa de probabilidade à esquerda na distribuição do período mais recente; fato que reforça uma piora nas práticas de oferta de serviços de ensino superior e de produção acadêmica para grande parte das DMUs. Por outro lado, a característica trimodal da distribuição para o ano de 2012, também revela a presença de dois grupos (clubes) de poucos departamentos que se mantém mais à direita da distribuição, isto é, com melhores práticas produtivas.

Os achados nas Figuras 1(c) e 1(d) indicam que não há diferença estatística entre as distribuições dos indicadores de eficiência entre departamentos de IES privadas e de IES públicas. Ou seja, nos períodos investigados, não há evidência de que o desempenho das unidades departamentais esteja associado a diferenças administrativas entre IES privadas e públicas, pelo menos no que tange a uma comparação incondicional.

Uma questão importante que pode influenciar o desempenho dos departamentos de economia refere-se a qualidade dos alunos ingressantes nos cursos de graduação, em particular, no que se refere às habilidades inatas e conhecimentos adquiridos, sobretudo em Matemática, durante o ensino médio (Johnes 2006b). Uma vez que, por indisponibilidade de informações sobre as notas de entradas dos alunos, as estimativas de indicadores de eficiência técnica desse trabalho não incorporaram nenhum input que potencialmente ponderasse tais aspectos, a estratégia adotada foi a de correlacionar possíveis influências da qualidade do corpo discente usando análise de regressão, levando em conta três proxies: diferenças relativas de remuneração observadas nos mercados regionais de trabalho (salário relativo do economista), reputação da IES (medido pelo IGC) e o nível de habilidade cognitiva dos alunos no 
componente de conhecimento geral do ENADE.

Nesse sentido, a Figura 2 apresenta resultados de uma exploração inicial na busca de alguma associação estatística entre escores de eficiência técnica dos departamentos de economia ${ }^{19}$ e as diferentes variáveis proxies utilizadas para a qualidade dos alunos. Note-se que os dados de dispersão entre as variáveis em destaque são separados por período de análise e incluem ajustamentos de curvas não paramétricas com intervalo de confiança (95\%) obtidas com o uso de regressão polinomial local.

Figura 2: Escores de eficiência técnica versus variáveis proxies para a qualidade dos discentes, 2009 e 2012

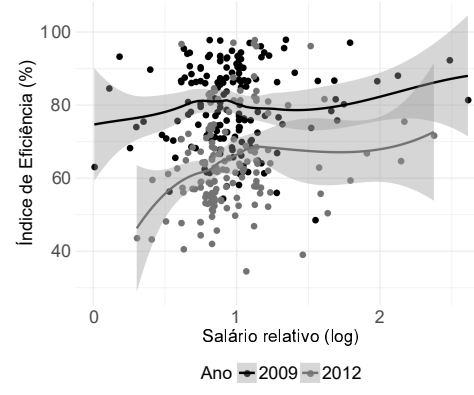

(a) Salário relativo

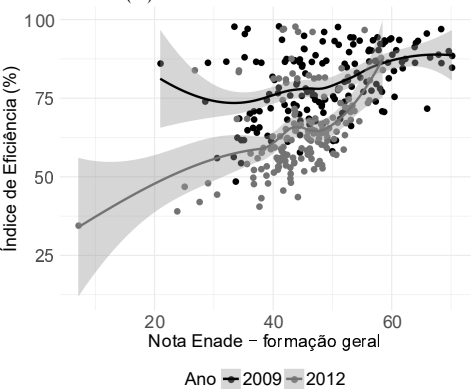

(c) Habilidade cognitiva

Fonte: Elaboração própria. As curvas e os seus intervalos de confiança (95\% de confiança) são ajustadas por regressão polinomial local.

Embora não se caracterize como uma evidência robusta, os dados, em especial, para o ano de 2012 sugerem uma associação direta entre eficiência dos departamentos de economia e a qualidade dos alunos. Essa relação fica mais notória na Figura 2(c), em que a qualidade do discente é captada pelo desempenho dos discentes do curso no componente de formação geral do ENADE, questões que não são competências especificamente trabalhadas no curso de Ciências Econômicas. Nas outras duas Figuras (2(a) e 2(c)) as relações não são muito bem definidas, muito embora os municípios cujos mercados de trabalho praticam remuneração relativas acima do centro da distribuição geral de salários para ocupações de nível superior observa-se uma relação positiva com a eficiência.

Os resultados apresentados até aqui referem-se aos indicadores de eficiência técnica auferidos pelas unidades departamentais dos cursos de economia,

\footnotetext{
${ }^{19}$ Considerando a baixa variabilidade nos escores de eficiência de escala e índices com valores maiores que $90 \%$ (em média), a análise de segundo estágio se concentra no indicador de eficiência técnica.
} 
contudo assumindo implicitamente que as DMUs defrontam-se com as mesmas condições de partida. Não obstante, fatores relativos ao perfil dos alunos (qualidade do discente e atributos socioeconômicos), características específicas das IES e outras variáveis omitidas não foram consideradas, de maneira que tais fatos podem influir na hipótese de homogeneidade de condições externas as DMUs e, assim, na eficiência técnica que pode ser atribuída a gestão dos departamentos.

Dessa maneira, considerando a heterogeneidade de condições de iniciais entre os diferentes departamentos de economia do Brasil, incluindo indicadores de qualidade do discente (expectativa salarial, reputação da IES e habilidade coginitiva), perfil dos alunos e professores, assim como, características da IES, a Tabela 5 apresenta sete modelos de regressão. Os Modelos 1, 2 e 3 são direcionados a uma análise com dados agrupados dos dois períodos, enquanto os demais modelos referem-se aos coeficientes obtidos por meio de um painel balanceado com efeito fixo. Além da diferenciação do controle para efeito fixo, os modelos possuem diferentes especificações para os indicadores que medem a qualidade do discente.

O nível de ajustamento dos modelos, medido pelo coeficiente de determinação $\left(R^{2}\right)$ ajustado varia de $23,8 \%$ a $68,1 \%$, sendo o Modelo 7 o que apresenta o maior grau de qualidade por esse indicador. Os modelos relativamente mais "ingênuos" não controlam parte dos fatores não observados (sobretudo, aqueles que são fixos no tempo), entretanto, permitem identificar correlações de alguns fatores interessantes para o entendimento do desempenho dos departamentos dos cursos de economia.

Nos Modelos 1, 2 e 3, após condicionar o índice de eficiência técnica por um conjunto de variáveis observadas, percebe-se que os departamentos pertencentes às instituições públicas possuem, em geral, um desempenho médio inferior aos cursos de economia providos por instituições privadas. Conforme o Modelo 3, por exemplo, as IES públicas apresentam, em média, um escore de eficiência 4,5 pontos percentuais (p.p.) menor que o observado pelas IES privadas. Um fato relevante no período estudado diz respeito ao processo de recomposição na oferta dos cursos de economia no Brasil (ver Tabela 4), em que, na média, pode ter gerado uma piora de performance relativa das instituições públicas. Isso pode ser melhor compreendido pelo fato das instituições privadas terem passado por uma redução no quantitativo total de departamentos de economia entre 2009 e 2012, provavelmente assegurando a sobrevivência de cursos mais rentáveis. Por outro lado, houve um processo de crescimento do número de departamentos em IES públicas em $65 \%$, fruto de uma política de expansão do governo de cursos superiores, onde essa maior ineficiência pode estar também associada ao problema de escala - o número de IES com retornos de escala crescente aumentou de 25 para 48 no período.

Das covariadas incluídas nos modelos com controle para efeito fixo (do 4 ao 7), representadas basicamente pelo perfil socioeconômico do aluno, atributos dos docentes e dos cursos, de modo geral observou-se de forma mais estável a significância estatística de variáveis relacionadas ao background socioeconômico do aluno - como raça, escolaridade da mãe e renda familiar -, a infraestrutura das IES e o total de alunos. De acordo com as estimativas, departamentos que apresentam alunos com condições socioeconômicas mais desfavoráveis tendem a possuir menores níveis de eficiência técnica. Os percentuais de alunos negros e mães com baixa escolaridade (com ensino primário incompleto) mostraram-se correlacionados negativamente, em média, 
Tabela 5: Resultados dos modelos de regressão. Variável dependente: escore de eficiência técnica (em \%)

\begin{tabular}{|c|c|c|c|c|c|c|c|}
\hline Covariadas & (1) & $(2)$ & (3) & $\begin{array}{c}\text { Modelo } \\
\text { (4) }\end{array}$ & (5) & $(6)$ & (7) \\
\hline \multicolumn{8}{|l|}{ Atributos dos alunos } \\
\hline Raça (negra) & $-0,2360^{* *}$ & $-0,2550^{* * * *}$ & $-0,2440^{* * * *}$ & $-0,3320^{* *}$ & $-0,3470^{* *}$ & $-0,3240^{* * * *}$ & $-0,3210^{* * *}$ \\
\hline Apoio social da IES & 0,0500 & 0,0410 & 0,0730 & 0,0470 & 0,0170 & 0,0040 & $-0,0040$ \\
\hline Pai com baixa escolaridade & 0,0120 & $-0,0060$ & $-0,0240$ & $-0,0490$ & $-0,0260$ & $-0,0470$ & $-0,0610$ \\
\hline Mãe com baixa escolaridade & $-0,1900^{* * *}$ & $-0,1860^{* * * *}$ & $-0,1420^{* * *}$ & $-0,2060^{* *}$ & $-0,2360^{* *}$ & $-0,1360^{* *}$ & $-0,1180^{*}$ \\
\hline Estuda no turno da noite & $-0,0600^{* *}$ & $-0,0390$ & $-0,0250$ & $-0,0420$ & 0,0450 & $-0,0470$ & $-0,0770$ \\
\hline Família com alta renda & $0,2050^{* * *}$ & $0,1580^{* * *}$ & $0,0910^{*}$ & $0,2970^{* * *}$ & $0,2900^{* * *}$ & $0,1420^{*}$ & $0,1330^{*}$ \\
\hline Ensino médio em escola pública & $-0,0100$ & 0,0060 & 0,0040 & 0,0580 & 0,0670 & $-0,0280$ & $-0,0120$ \\
\hline Salário relativo & $4,6190^{* * *}$ & & & $11,1330^{* *}$ & & & $0,4780^{*}$ \\
\hline Salário-hora & $-0,8120^{* *}$ & & & $-1,4950$ & & & $-0,0640$ \\
\hline Salário-hora ao quadrado & 0,0030 & & & 0,0060 & & & 0,0040 \\
\hline Taxa de economistas na FT & 0,3250 & & & $-0,3030$ & & & $-0,1300$ \\
\hline Taxa de economistas na FT (ao quadrado) & $-0,0060^{*}$ & & & 0,0003 & & & 0,0005 \\
\hline Reputação da IES & & 1,1390 & & & $-0,0460$ & & $-4,9280$ \\
\hline Habilidade cognitiva: formação geral & & & $0,8710^{* * * *}$ & & & $1,1510^{* * *}$ & $1,1530^{* * *}$ \\
\hline \multicolumn{8}{|l|}{ Características do corpo docente e da IES } \\
\hline Idade dos docentes & $-4,6210^{*}$ & $-4,7680^{*}$ & $-4,8230^{* *}$ & $-5,9500$ & $-5,5260$ & $-0,0650$ & $-0,9260$ \\
\hline Idade dos docentes ao quadrado & 0,0440 & $0,0460^{*}$ & $0,0480^{* *}$ & 0,0590 & 0,0550 & $-0,0070$ & 0,0010 \\
\hline Docentes com bolsa de pesquisa & 0,0060 & 0,0200 & 0,0570 & $-0,2060$ & $-0,2260^{*}$ & $-0,0720$ & $-0,0390$ \\
\hline Razão docente/servidor técnico & 0,5790 & 0,5770 & 0,4950 & 1,2560 & 1,0320 & $2,0450^{* *}$ & $2,0840^{* *}$ \\
\hline Baixa infraestrutura da IES & $-0,0710$ & $-0,0700$ & $-0,0910^{* *}$ & $-0,1590^{*}$ & $-0,1660^{*}$ & $-0,1410^{* *}$ & $-0,1300^{* *}$ \\
\hline Total de alunos $(\log )$ & $-0,9370$ & $-1,0820$ & $-1,3320^{* *}$ & $-10,1240^{* *}$ & $-11,2230^{* * *}$ & $-9,5350^{* * *}$ & $-9,4610^{* * *}$ \\
\hline Tempo de criação do curso & $-0,0230$ & $-0,0160$ & $-0,0480$ & & & & \\
\hline IES pública & $-4,5560^{* *}$ & $-3,5390$ & $-4,4730^{* *}$ & & & & \\
\hline Centro-Oeste & $12,4900^{* * *}$ & $8,1290^{* *}$ & $5,8020^{*}$ & & & & \\
\hline Nordeste & 3,6230 & 4,2190 & 4,6620 & & & & \\
\hline Sudeste & $7,2910^{* *}$ & 5,0490 & $3,0530^{*}$ & & & & \\
\hline Sul & 4,3540 & 0,9710 & $-0,8770$ & & & & \\
\hline Capital estadual & 3,7180 & $-0,3780$ & 1,9360 & & & & \\
\hline Intercepto & $216,3830^{* * *}$ & $215,1610^{* * *}$ & $179,5270^{* * *}$ & & & & \\
\hline Efeito fixo & & & & $\mathrm{X}$ & $\mathrm{X}$ & $\mathrm{X}$ & $\mathrm{X}$ \\
\hline $\mathrm{N}$ & 292,0000 & 287,0000 & 292,0000 & 264,0000 & 264,0000 & 264,0000 & 264,0000 \\
\hline $\mathrm{R}^{2}$ & 0,2380 & 0,1730 & 0,4220 & 0,3500 & 0,2750 & 0,6730 & 0,6810 \\
\hline
\end{tabular}

Fonte: Elaboração própria.

Nota: ${ }^{* * *}$ Estatisticamente significativo a $1 \% .{ }^{* *}$ Estatisticamente significativo a 5\%. ${ }^{*}$ Estatisticamente significativo a $10 \%$. FT $=$ Força de trabalho 
com o desempenho relativo das DMUs, ao passo que departamentos com uma maior composição de alunos com renda familiar de seis salários mínimos ou mais apresentam maior eficiência. A correlação do background familiar e a eficiência está em consonância com evidências encontradas na literatura, visto que Sampaio et al. (2011), por exemplo, conseguem identificar um papel importante das condições dos alunos na evasão do ensino superior e, complementarmente, na taxa de conclusão - que compõe um dos outputs do modelo de eficiência utilizado.

As instituições que apresentaram baixas condições gerais das instalações físicas de salas de aula, bibliotecas e ambientes de trabalho e estudo para o funcionamento do curso de economia possuíram menores níveis de eficiência, sinalizando que a infraestrutura dos cursos podem ser importantes para a ampliação da produtividade dos departamentos. Contudo, uma redução marginal de $1 \%$ no percentual de cursos com condições de infraestrutura desfavoráveis geram uma baixa repercussão na eficiência técnica. De acordo ainda com os resultados dos Modelo 6 e 7, as DMUs com uma maior razão docente por servidor técnico administrativo são mais eficientes. Esse fator mede, em certo grau, a organização da hierarquia superior ao departamento (gestão da IES). Dessa forma, os cursos ofertados em IES com melhor gerenciamento relativo do corpo docente apresentam incrementos de 1,32 p.p. na eficiência departamental, em face a uma sinalização de recursos da instituição pró capital humano responsável pela pesquisa e ensino.

Em relação às variáveis regionais (observáveis fixas no tempo) presentes nos Modelo 1 a 3, ressalta-se que os cursos de economia providos por departamentos situados nas regiões Centro-Oeste e Sudeste possuem uma maior eficiência, em média, do que departamentos localizados em outras regiões do país - em geral, locais com menor nível de desenvolvimento. Tais achados podem estar associados a possibilidade desses departamentos conseguirem atrair alunos e docentes mais hábeis, em decorrência do ambiente econômico mais dinâmico, como realçado por Bartalotti \& Menezes Filho (2007) e Avkiran (2011), em termos das condições do mercado de trabalho para a escolha dos indivíduos por uma profissão e das oportunidades de obtenção de financiamento de projetos de pesquisa.

Considerando que uma demanda de alunos mais hábeis e motivados pelo curso de economia afeta positivamente a performance das DMUs, este estudo utilizou três tipos de proxies para condicionar a eficiência técnica pelo nível de qualidade do discente: indicadores de mercado de trabalho, reputação da IES e a nota do ENADE no componente de formação geral (habilidade cognitiva). De forma global, departamentos situados em locais com maior salário relativo e que possuem alunos com maior proficiência no ENADE no componente geral têm maior escore de eficiência técnica, já a variável que mede a reputação da IES - por meio do indicador de qualidade das instituições utilizado pelo INEP - não se mostrou significativo estatisticamente em nenhuma das especificações.

Dessa forma, os Modelos 4 e 7, com efeito fixo dos departamentos, aponta que locais em que a profissão de economista possui maior expectativa salarial às outras ocupações de nível superior (salário relativo), o nível de eficiência departamental é maior, com uma elasticidade que varia de $0,2 \%$ (Modelo 7) a 0,43\% (Modelo 4). Em igual direção de sinal, estima-se uma elasticidade de 0,75\% (Modelos 6 e 7) para variável de proficiência do ENADE no componente geral. Esses resultados ratificam a tendência de relação positiva entre essas 
variáveis e o nível de eficiência, como visto visualmente nas Figuras 2(a) e 2(c). Todavia, no caso dos coeficientes das regressões dispostos na Tabela 5, isso é constatado com base em um controle para outras variáveis observadas e não observadas (efeitos heterogêneos específicos dos departamentos).

Portanto, os níveis de eficiência dos departamentos de economia, independente da especificação utilizada, apresentaram correlação, em especial, com às variáveis relacionadas aos atributos dos alunos. Essas evidências, em consonância com a literatura internacional da área (Johnes 2006b), sugerem uma importância da qualidade do corpo discente, fator não controlável diretamente pelas gestões dos departamentos, para uma análise mais justa entre as diferentes DMUs no que concerne à relação comparativa de insumos e produtos.

\section{Considerações Finais}

Esse artigo analisou o nível de eficiência dos cursos de economia no Brasil, levando em consideração o papel de variáveis contextuais relacionadas à qualidade do corpo discente e das IES. Usando dados provenientes de diversas fontes, a saber CES e ENADE do INEP, RAT/CAPES, DGP/CNPq e da RAIS/MTE, foram estimados indicadores de eficiência para unidades departamentais com um modelo DEA de fronteira sequencial com correção de viés por reamostragens (bootstrap). Ademais, em segunda etapa, os indicadores de eficiência técnica corrigidos de viés foram condicionados a um conjunto de variáveis contextuais a partir de um modelo de regressão com efeitos fixos.

Os resultados mostraram uma alteração significativa da distribuição de desempenho das unidades departamentais entre os anos de 2009 e 2012, com uma redução de eficiência técnica em cerca de $20 \%$ no período avaliado, com os departamentos exibindo, em média, um nível de eficiência técnica de 64,4\%, no último período. Em geral, houve uma maior concentração de DMUs com práticas de ensino e produção científica relativamente piores às práticas de referência, dados os níveis de inputs. Tal evidência foi acompanhada por uma redução importante no número de departamentos de economia associados às IES privadas e crescimento daqueles vinculados às IES públicas, assim como foram constatadas: (i) forte diminuição da nota média dos concluintes de graduação no ENADE, sobretudo nas IES públicas; (ii) elevação da média de docentes com doutorado nos departamentos de IES privadas e (iii) significativa redução da média de graduados nos departamentos de IES públicas. Essa mudança nos indicadores de eficiência no período investigado pode estar relacionada com intervenções governamentais no mercado de educação superior (como os programas federais REUNI e PROUNI), que podem ter repercutido na composição da oferta dos cursos de economia e nos indicadores acadêmicos, sobretudo, em 2012.

A identificação de um elevado percentual de departamentos operando com ineficiência de escala, além de problemas relacionados com baixa produção relativa dado os insumos empregados, mostra-se importante para orientar o planejamento e resultados desejados pelos departamentos de economia no curto e longo prazo. Como um percentual considerável da oferta dos cursos de economia é de responsabilidade de IES públicas, os ajustamentos nos insumos, especialmente, no quadro de docentes pode ser um processo mais demorado dada às amarras legais e burocráticas do setor público brasileiro, sendo um exercício mais complexo o processo de reestruturação das escalas de opera- 
ção. Quanto a questão da ineficiência técnica, as alterações podem ser providas, relativamente, em um menor espectro de tempo, de modo que a gestão dos departamentos de economia podem tentar gerar incentivos para ampliar a produção, atualizar a grade curricular e melhorar os indicadores de conclusão dos cursos.

Os resultados encontrados, no primeiro estágio, sugerem que as ineficiências dos departamentos de economia estão mais relacionadas com desperdícios do que a problemas na escala de funcionamento dos departamentos, visto que a eficiência de escala, em média, foi superior a $93 \%$ em todo o período. As evidências providas pela abordagem DEA se mostram relevantes para os gestores dos departamentos no sentido de melhor entender as ineficiências com base em DMUs pertencentes a um mesmo conjunto de referência (unidades eficientes com conjunto similar de entradas e saídas) e melhorar a utilização dos recursos escassos.

No que tange às principais evidências do segundo estágio, os escores de eficiência técnica se mostraram correlacionados com o background socioeconômico dos discentes, evidenciando que departamentos compostos por alunos com condições sociais mais favoráveis tendem a apresentar, em média, uma maior produtividade relativa. Ademais, as proxies utilizadas para captar à qualidade do corpo discente, particularmente o salário relativo e a habilidade cognitiva dos alunos, também se associaram positivamente com o indicador de eficiência, indicando a importância de se ponderar o desempenho das DMUs por fatores não controláveis diretamente pela gestão departamental e, assim, prover uma melhor comparabilidade entre os diferentes departamentos.

Por fim, ressaltam-se que os esforços empreendidos nesta pesquisa não esgotam as discussões sobre a eficiência dos recursos na provisão de ensino superior na área de economia, tendo em vista às limitações das variáveis utilizadas nesta pesquisa (em ambos os estágios), pelo período de tempo estudado ou pela falta de aprofundamento de alguns resultados - como a medição do impacto dos programas federais no mercado de educação superior no Brasil e seus efeitos nos resultados de ensino e pesquisa. Contudo, considerando a escassez de pesquisas no país com esse enfoque específico para estudar a eficiência da provisão de cursos, como o de economia, a presente análise mensurou o desempenho relativo dos departamentos. Enquanto unidades tomadoras de decisão, alguns departamentos de economia podem empregar os insumos disponíveis de modo a produzir resultados mais eficientes nas dimensões de ensino e pesquisa, em que as práticas de excelência podem servir de referência para outras unidades se ajustarem na busca de melhores resultados e orientar políticas governamentais na área de educação superior.

\section{Referências Bibliográficas}

Avkiran, N. K. (2011), Applications of data envelopment analysis in the service sector, in W. W. Cooper, L. M. Seiford \& J. Zhu, eds, 'Handbook on Data Envelopment Analysis', 2 edn, Springer, New York, chapter 15, pp. 403-443.

Aziz, N. A. A., Janor, R. M. \& Mahadi, R. (2013), 'Comparative departmental efficiency analysis within a university: a DEA approach', Procedia - Social and Behavioral Sciences 90(InCULT 2012), 540-548. 
Banker, R. D., Charnes, A. \& Cooper, W. (1984), 'Some models for estimating technical and scale inefficiencies in data envelopment analysis', Management Science 30(9), 1078-1092.

Bartalotti, O. \& Menezes Filho, N. (2007), 'A relação entre o desempenho da carreira no mercado de trabalho e a escolha profissional dos jovens', Economia Aplicada 11(4), 487-505.

Belloni, J. A. (2000), Uma metodologia de avaliação da eficiência produtiva de universidades federais brasileiras, Doutorado, Universidade Federal de Santa Catarina.

Betts, J. R. (1996), 'What do students know about wages? evidence from a survey of undergraduates', The Journal of Human Resources 31(1), 27-56.

Bogetoft, P. \& Otto, L. (2011), Benchmarking with DEA, SFA, and R, Springer, New York, vol. 157.

Casado, F. L. \& Siluk, J. C. M. (2012), Aferição da eficiência técnica em cursos de engenharia de produção do Brasil, in 'XXXII Encontro Nacional de Engenharia de Produção', ENEGEP, Bento Gonçalves, p. 15.

Casado, F. \& Souza, A. (2007), 'Análise envoltória de dados: conceitos, metodologia e estudo da arte na educação superior', Revista do Centro de Ciências Sociais p. 17.

Charnes, A., Cooper, W. \& Rhodes, E. (1978), 'Measuring the efficiency of decision making units', European Journal of Operational Research 2(6), 429444.

Cooper, W. W., Seiford, L. M. \& Zhu, J. (2011), Handbook on data envelopment analysis, 2 edn, Springer, New York.

Costa, E. M., de Souza, H. R., Ramos, F. d. S. \& da Silva, J. L. M. (2012), 'Eficiência e desempenho no ensino superior: uma análise da fronteira de produção educacional das IFES brasileiras', Rev. Econ. Contemp. 16(3), 415440 .

Costa, E. M., Ramos, F. d. S., de Souza, H. R. \& Sampaio, L. M. B. (2015), 'Dinâmica da eficiência produtiva das instituições federais de ensino superior', Planejamento e Políticas Públicas 44(jan./jun.), 51-84.

de Castro, N. J. (2001), O economista: a história da profissão no Brasil, 1 edn, Corecon-SP, São Paulo.

Façanha, L. O. \& Marinho, A. (2001), 'Instituições de ensino superior governamentais e particulares: avaliação comparativa de eficiência', Texto para Discussão IPEA (813), 1-33.

Färe, R. \& Grosskopf, S. (1996), Intertemporal production frontiers: with dynamic DEA, Kluwer Aca, Norwell.

Färe, R., Grosskopf, S., Norris, M. \& Zhang, Z. (1994), 'Productivity growth, technical progress, and efficiency change in industrialized countries', The American Economic Review 84(1), 66-83. 
Ferreira, C. M. d. C. \& Gomes, A. P. (2009), Introdução à análise envoltória de dados, UFV, Viçosa.

Halkos, G. E., Nickolaos, G. \& Kourtzidis, S. A. (2012), 'Measuring public owned university departments' efficiency: a bootstrapped dea approach', Journal of Economics and Econometrics 55(2), 1-24.

Johnes, J. (2006a), 'Data envelopment analysis and its application to the measurement of efficiency in higher education', Economics of Education Review 25(3), 273-288.

Johnes, J. (2006b), 'Measuring teaching efficiency in higher education: an application of data envelopment analysis to economics graduates from UK Universities 1993', European Journal of Operational Research 174(1), 443-456.

Joumady, O. \& Ris, C. (2005), 'Performance in European higher education: a non-parametric production frontier approach', Education Economics 13(2), 189-205.

Kao, C. \& Hung, H.-T. (2008), 'Efficiency analysis of university departments: an empirical study', Omega 36(4), 653-664.

Maddena, G., Savagea, S. \& Kempa, S. (1997), 'Measuring public sector efficiency: a study of economics departments at Australian universities', Education Economics 5(2), 153-168.

Montmarquette, C., Cannings, K. \& Mahseredjian, S. (2002), 'How do young people choose majors?', Economics of Education Review 21(6), 543-556.

Novaes, W. (2008), 'A pesquisa em economia no Brasil: uma avaliação empírica dos conflitos entre quantidade e qualidade', Revista Brasileira de Economia 62(4), 467-495.

Organization for Economic Co-operation and Development (2014), PISA 2012 Results in Focus, OECD, Washington, D.C.

Sampaio, B., Sampaio, Y., de Mello, E. P. \& Melo, A. S. (2011), 'Desempenho no vestibular, background familiar e evasão: evidências da UFPE', Economia Aplicada 15(2), 287-309.

Sarkis, J. (2006), Preparing your data for DEA, in N. K. Avkiran, ed., 'Productivity Analysis in the Service Sector with Data Envelopment Analysis', 3 edn, UQ Business School, Brisbane, chapter 12, pp. 115-124.

Simar, L. \& Wilson, P. W. (1998), 'Sensitivity analysis of efficiency scores: how to bootstrap in nonparametric frontier models', Management Science 44(1), 49-61.

Simar, L. \& Wilson, P. W. (2000), 'A general methodology for bootstrapping in non-parametric frontier models', Journal of Applied Statistics 27(6), 779802.

Simar, L. \& Wilson, P. W. (2008), Statistical inference in non-parametric frontier models: recent developments and perspectives, in H. O. Fried, C. A. K. Lovell \& S. S. Schmidt, eds, 'The Measurement of Productive Efficiency and Productivity Change', 1 edn, number January, Oxford University Press, chapter 4 . 
Souza, C. D., Filippo, D. \& Casado, E. (2015), 'Impacto do programa de apoio a planos de reestruturação e expansão das universidades federais brasileiras (reuni) na atividade investigativa: crescimento, qualidade e internacionalização', Em Questão 21(3), 336-367.

Tulkens, H. \& Vanden Eeckaut, P. (1995), 'Non-parametric efficiency, progress and regress measures for panel data: methodological aspects', European Journal of Operational Research 80(3), 474-499.

Walsh, S., Flannery, D. \& Cullinan, J. (2017), 'Analysing the preferences of prospective students for higher education institution attributes', Education Economics pp. 1-18.

Wooldridge, J. M. (2010), Econometric analysis of cross section and panel data, 2 edn, MIT Press.

Worthington, A. C. \& Lee, B. L. (2008), 'Efficiency, technology and productivity change in Australian universities, 1998-2003', Economics of Education Review 27(3), 285-298.

\section{Apêndice A Apêndice}

Figura A.1: Comparação entre as distribuições dos escores de eficiência entre os modelos com e sem bootstrap entre 2009 e 2012

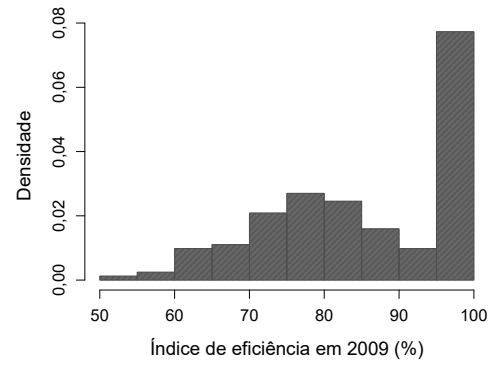

(a) Sem bootstrap: 2009

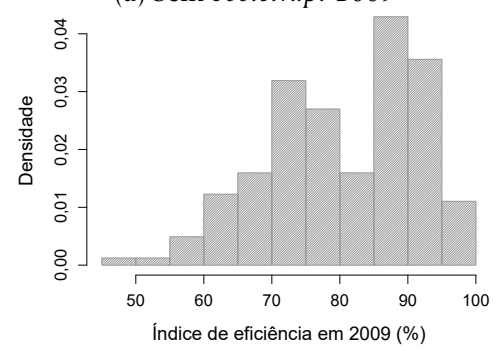

(c) Com bootstrap: 2009

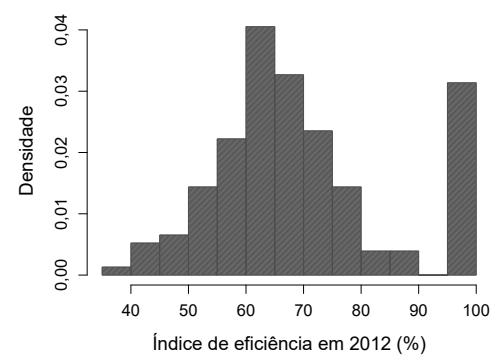

(b) Sem bootstrap: 2012

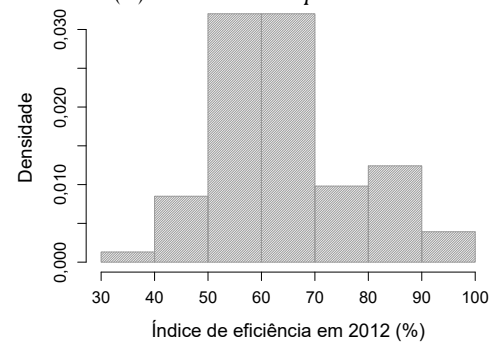

(d) Com bootstrap: 2012 
Tabela A.1: Estatísticas descritivas para as variáveis explicativas usadas no modelo de regressão

\begin{tabular}{|c|c|c|c|c|c|c|}
\hline \multirow[b]{2}{*}{ Variável explicativa } & \multicolumn{2}{|c|}{2009} & \multicolumn{2}{|c|}{2012} & \multicolumn{2}{|c|}{ Diferença } \\
\hline & Média & DP & Média & DP & Valor & p-valor \\
\hline Percentual de alunos da cor negra & 6,990 & 10,960 & 6,630 & 8,080 & $-0,360$ & 0,734 \\
\hline $\begin{array}{l}\text { Percentual de alunos que recebem } \\
\text { apoio social da instituição }\end{array}$ & 3,180 & 13,320 & 5,910 & 18,990 & 2,730 & 0,128 \\
\hline $\begin{array}{l}\text { Percentual de pais dos alunos com en- } \\
\text { sino primário incompleto }\end{array}$ & 31,810 & 20,750 & 26,690 & 16,480 & $-5,120$ & 0,014 \\
\hline $\begin{array}{l}\text { Percentual de mães dos alunos com en- } \\
\text { sino primário incompleto }\end{array}$ & 26,850 & 19,450 & 20,420 & 15,520 & $-6,430$ & 0,001 \\
\hline $\begin{array}{l}\text { Percentual de alunos matriculados no } \\
\text { turno da noite }\end{array}$ & 80,520 & 34,200 & 78,360 & 35,210 & $-2,160$ & 0,567 \\
\hline $\begin{array}{l}\text { Percentual de alunos com renda fami- } \\
\text { liar com } 6 \text { salários mínimos ou mais }\end{array}$ & 43,250 & 22,810 & 42,800 & 22,080 & $-0,450$ & 0,857 \\
\hline $\begin{array}{l}\text { Percentual de alunos que estudaram o } \\
\text { ensino médio em escola pública }\end{array}$ & 59,860 & 26,340 & 57,140 & 25,440 & $-2,720$ & 0,341 \\
\hline $\begin{array}{l}\text { Salário do economista relativo a outras } \\
\text { profissões }\end{array}$ & 2,850 & 1,470 & 2,760 & 1,200 & $-0,090$ & 0,550 \\
\hline Salário-hora do economista & 23,030 & 9,580 & 23,500 & 9,670 & 0,470 & 0,654 \\
\hline $\begin{array}{l}\text { Participação do economista na força de } \\
\text { trabalho (por } 10 \text { mil trabalhadores) }\end{array}$ & 18,760 & 10,900 & 19,230 & 10,570 & 0,470 & 0,686 \\
\hline $\begin{array}{l}\text { Reputação da IES (Índice Geral de Cur- } \\
\text { sos) }\end{array}$ & 2,610 & 0,660 & 2,810 & 0,720 & 0,200 & 0,009 \\
\hline Nota do ENADE: formação geral & 48,440 & 10,160 & 44,270 & 7,060 & $-4,170$ & 0,000 \\
\hline Média da idade do corpo docente & 44,790 & 5,140 & 45,480 & 4,480 & 0,690 & 0,185 \\
\hline $\begin{array}{l}\text { Percentual de docentes com bolsa de } \\
\text { pesquisa }\end{array}$ & 2,270 & 5,850 & 6,260 & 14,180 & 3,990 & 0,001 \\
\hline $\begin{array}{l}\text { Razão docente-servidores técnicos da } \\
\text { IES }\end{array}$ & 1,610 & 1,340 & 1,410 & 0,790 & $-0,200$ & 0,085 \\
\hline $\begin{array}{l}\text { Percentual de alunos que acham a in- } \\
\text { fraestrutura inadequada do curso }\end{array}$ & 24,340 & 22,590 & 19,310 & 19,660 & $-5,030$ & 0,032 \\
\hline Total de alunos ingressantes na IES & 4267,570 & 9139,050 & 5679,850 & 14786,210 & 1412,280 & 0,294 \\
\hline $\begin{array}{l}\text { Tempo de criação do curso de gradua- } \\
\text { ção }\end{array}$ & 38,230 & 18,720 & 39,840 & 19,510 & 1,610 & 0,451 \\
\hline Percentual de instituição pública & 33,710 & 47,400 & 42,680 & 49,610 & 8,970 & 8,869 \\
\hline $\begin{array}{l}\text { Percentual de departamentos na Re- } \\
\text { gião Norte }\end{array}$ & 8,430 & 27,860 & 7,320 & 26,120 & $-1,110$ & 70,401 \\
\hline $\begin{array}{l}\text { Percentual de departamentos na Re- } \\
\text { gião Nordeste }\end{array}$ & 15,170 & 35,970 & 15,850 & 36,640 & 0,680 & 86,175 \\
\hline $\begin{array}{l}\text { Percentual de departamentos na Re- } \\
\text { gião Sudeste }\end{array}$ & 42,700 & 49,600 & 43,900 & 49,780 & 1,200 & 82,276 \\
\hline $\begin{array}{l}\text { Percentual de departamentos na Re- } \\
\text { gião Sul }\end{array}$ & 23,600 & 42,580 & 24,390 & 43,070 & 0,790 & 86,401 \\
\hline $\begin{array}{l}\text { Percentual de departamentos na Re- } \\
\text { gião Centro-Oeste }\end{array}$ & 10,110 & 30,230 & 8,540 & 28,030 & $-1,570$ & 61,728 \\
\hline $\begin{array}{l}\text { Percentual de departamentos na capi- } \\
\text { tal estadual }\end{array}$ & 46,630 & 50,030 & 47,560 & 50,090 & 0,930 & 86,357 \\
\hline Observações & \multicolumn{2}{|c|}{163,00} & \multicolumn{2}{|c|}{152,00} & & \\
\hline
\end{tabular}


Tabela A.2: Lista dos 20 Departamentos de Economia mais e menos eficientes em 2012, painel balanceado (132 observações por ano), dados ordenados pelo escore de eficiência técnica sem viés (DEA-S bootstrap)

\begin{tabular}{|c|c|c|c|c|c|c|c|c|c|}
\hline \multicolumn{4}{|c|}{ Mais eficientes } & \multirow[b]{2}{*}{ Var. $(\%)$} & \multicolumn{5}{|c|}{ Menos eficientes } \\
\hline & IES & UF & $\theta_{\mathbf{b c}}$ & & & IES & UF & $\theta_{\mathbf{b c}}$ & Var.(\%) \\
\hline 1,00 & FECEA $^{C}$ & PR & 96,98 & 8,91 & 113,00 & $\mathrm{UESB}^{C}$ & BA & 52,61 & $-32,81$ \\
\hline 2,00 & FIP $^{C}$ & $\mathrm{~PB}$ & 96,23 & 10,88 & 114,00 & $\mathrm{FAE}^{C}$ & PR & 52,52 & $-33,42$ \\
\hline 3,00 & UNEMAT $^{C}$ & MT & 96,16 & 36,20 & 115,00 & $\mathrm{UCPEL}^{C}$ & RS & 52,42 & $-26,23$ \\
\hline 4,00 & $\mathrm{UVV}^{*}$ & SP & 84,59 & $-1,99$ & 116,00 & CIESA $^{D}$ & AM & 52,35 & $-14,70$ \\
\hline 5,00 & UFRJ $^{*}$ & ES & 84,55 & $-11,72$ & 117,00 & UNISANT. $^{C}$ & $\mathrm{SP}$ & 51,51 & $-22,97$ \\
\hline 6,00 & IBMEC $^{*}$ & $\mathrm{RJ}$ & 84,16 & $-3,40$ & 118,00 & UESC $^{C}$ & BA & 51,12 & $-28,43$ \\
\hline 7,00 & UNESP* & MG & 84,11 & $-11,07$ & 119,00 & $\mathrm{UFS}^{C}$ & SE & 50,54 & $-22,26$ \\
\hline 8,00 & PUCSP ${ }^{*, 1}$ & SP & 83,35 & $-4,78$ & 120,00 & $\mathrm{UEL}^{C}$ & $\mathrm{PR}$ & 49,97 & $-42,01$ \\
\hline 9,00 & $\mathrm{UFC}^{*, 2}$ & $\mathrm{CE}$ & 82,40 & $-5,06$ & 121,00 & FEC-FAAPC & $\mathrm{SP}$ & 49,66 & $-26,99$ \\
\hline 10,00 & $\mathrm{EBEF}^{*}$ & RJ & 82,31 & $-7,39$ & 122,00 & UFCG $^{C}$ & $\mathrm{~PB}$ & 48,25 & $-46,62$ \\
\hline 11,00 & UNESC ${ }^{*}$ & $\mathrm{CE}$ & 81,54 & $-5,76$ & 123,00 & $\mathrm{UNIR}^{C}$ & RO & 48,11 & $-26,83$ \\
\hline 12,00 & $\mathrm{URCA}^{*, 3}$ & SC & 81,37 & $-10,42$ & 124,00 & $\mathrm{UFRPE}^{C, 4}$ & $\mathrm{PE}$ & 48,07 & $-21,99$ \\
\hline 13,00 & $\mathrm{UCAM}^{*}$ & RJ & 81,36 & 10,99 & 125,00 & $\mathrm{UNISO}^{C}$ & SP & 47,89 & $-23,54$ \\
\hline 14,00 & FESURV ${ }^{*}$ & MG & 81,16 & $-6,30$ & 126,00 & UFES $^{C}$ & ES & 47,15 & $-35,08$ \\
\hline 15,00 & N.PAIVA ${ }^{C}$ & RJ & 81,12 & 3,26 & 127,00 & UFRRJ $^{C}$ & RJ & 43,81 & $-40,93$ \\
\hline 16,00 & CESVA* & DF & 81,05 & $-6,17$ & 128,00 & UNITAU $^{D}$ & SP & 43,38 & $-44,10$ \\
\hline 17,00 & $\mathrm{UNB}^{*}$ & RS & 80,93 & $-6,96$ & 129,00 & $\mathrm{FOC}^{\mathrm{C}}$ & SP & 42,17 & $-47,01$ \\
\hline 18,00 & UFRGS* & GO & 80,80 & 43,88 & 130,00 & FURG $^{C}$ & RS & 40,67 & $-48,07$ \\
\hline 19,00 & FIVJ $^{*}$ & MG & 78,40 & $-13,50$ & 131,00 & UFMS $^{C}$ & MS & 39,45 & $-55,70$ \\
\hline 20,00 & UNINILT. $^{D}$ & $\mathrm{AM}$ & 77,93 & $-2,86$ & 132,00 & UEFS $^{C}$ & BA & 34,69 & $-48,26$ \\
\hline
\end{tabular}

Elaboração própria.

Nota: Var.(\%) refere-se a variação da eficiência entre 2009 e 2012.

Legenda: tipo de retorno de escala em 2012, $C=$ Crescente, ${ }^{*}=$ Constante e $D=$ Decrescente; nome do município

para os casos de IES com mais de um departamento: 1=São Paulo; $2=$ Fortaleza; $3=$ Criciúma; 4=Recife.

N.PAIVA=NEWTON PAIVA; UNINILT.=UNINILTONLINS; UNISANT.=UNISANT'ANNA 